\title{
Geothermal Electricity Generation, Challenges, Opportunities and Recommendations
}

\author{
Moses Jeremiah Barasa Kabeyi, \\ Department of Mechanical and Manufacturing Engineering \\ University of Nairobi, Kenya.
}

\begin{abstract}
Geothermal energy has a potential for several applications including geo-exchange, direct thermal application and power generation. Whereas the untapped capacity is over $100 \mathrm{GW}$ globally, its growth realizes only 3-4\% growth per year while the global share of electricity generation is less than 1\%. Limitations of geothermal energy include scarcity of exploitable sites, remote locations often far from load centers and undesirable gaseous emissions. Project development faces challenges of poor funding, technology and long gestation periods of between 5 and 10 years for conventional power plants. Smooth implementation of geothermal project requires, social acceptance, through minimization of environmental effect, avoidance of adverse effects on the people and giving direct benefits to local communities. It is through both subsurface and power plant technologies that environmental challenges of geothermal power plants are addressed. Research and development into new, efficient and costeffective technologies will enhance safety and environmental integrity with respect to geothermal energy and electricity development. A geothermal power plant project generally goes through exploration or prefeasibility stage, drilling or feasibility stage and development stage which involves development of production wells, reinjection wells, steam gathering system and power plant construction and commissioning. The last phase is power plant operation and maintenance before the plant is finally retired upon end of the generation contract or license. These phases of the cycle before generation all combined take relatively long and there is need to improve. The use of Wellhead power plants currently provide a quick access to geothermal electricity ahead of full development of a conventional power plant hence enabling quicker access to geothermal electricity. Drilling which is a critical process in geothermal resource exploration and development is expensive, and therefore development of geophysical methods to resolve this problem is highly desirable as it could significantly reduce the cost of geothermal energy development hence advanced technology in drilling and upfront activities will reduce costs and risks in development. Better technology in upfront activities will significantly reduce the high risks and costs while power plant conversion technologies and better reservoir management and engineering will increase output, resource availability and efficiency of resource exploitation. Geothermal energy resources are significant and if the technical, financial, environmental, social and logistical challenges are addressed, it can be a major player in global energy and electricity market as renewable, safe and cheap resources. Research and development of technology and solutions to current challenges should be enhanced. The study concluded that technical barriers, high financial costs and long gestation periods prevent faster development of geothermal electricity.
\end{abstract}

Key words: Geothermal Energy, Geothermal Heat Pumps, Geothermal Electricity, Geothermal Resources, Geothermal Power Plants Technology, Geothermal Wellhead Technology, Geothermal Project Cycles, Barriers to Geothermal Development, Challenges of Geothermal Energy.

\subsection{INTRODUCTION TO GEOTHERMAL ENERGY AND ELECTRICITY}

\subsection{Historical Perspective of Geothermal Energy and Power plants}

The first use of geothermal energy occurred more than 10,000 years ago in North America by American Paleo-Indians. People used water from hot springs for cooking, bathing and cleaning. The first industrial use of geothermal energy began near Pisa, Italy in late 18th century where steam coming from natural vents or drilled holes was used to extract boric acid from the hot pools that are now known as the Larderello fields. Geothermal resources for electric power production was conceptualized and studied by Prince Piero Ginori Conti at the beginning of the 20th century who on the July 4, 1904 commissioned the first experimental plant to demonstrate the possibility of exploitation of geothermal energy on a source located near Larderello, Tuscany, Italy. The construction consisted of a binary water cycle, producing pure steam to drive a piston engine coupled to a $10 \mathrm{~kW}$ dynamo generator powering 5 -wattage light bulbs that were electrically connected. 
The first commercial geothermal power plant in the world was the Larderello 1 which was s installed in 1913 and consisted of an indirect-cycle pure-steam process with a $250 \mathrm{~kW}$ backpressure steam turbine which was manufactured by Franco Tosi. The plant provided electricity to all the chemical plants of the Boraciferous region and with the first electrical line transferring geothermal power to the nearby villages of Pomarance and Volterra.

In the USA, the first geothermal plant started operations in 1922 with a capacity of 250 kilowatts. It produced little output but due to technical glitches, it had to be shut down. Direct-cycle geothermal technology was experimented in 1923 , by testing a 23 $\mathrm{kW}$ turbine in Serazzano, near Larderello but due to the very high chemical quality of the geothermal steam source, this unit ran without problems for almost two years. In the US, a $35 \mathrm{Kw}$ experimental station was stated at the Geysers, California in 1932 to provide power to a local resort.

In Italy, several extra installations were done, for a total of $123.9 \mathrm{MW}$. Of this amount $107 \mathrm{MW}$ was from binary system units and 16.9 MW came from backpressure steam turbines at the end of the year 1943. During the 1950s the commercial exploitation of geothermal sources began in other regions of the world, mainly with high-temperature resources, by installing dry steam or single-flash steam turbines. The Wairakei geothermal plant in New Zealand stated operations in 1958 while in 1959 , an experimental geothermal plant was commissioned at Pathe, in Mexico. In 1960, the first commercial geothermal plant in 1960 at the Geysers, California in USA.

During the 1960's, Pacific Gas and Electric began operation of first large scale geothermal power plant in San Francisco, producing 11 megawatts. In 1966, a 23 mw geothermal plant was commissioned in Japan at Matsukuwa. All the power plants except the one at Wairakei were dry steam plants. The plant at Wairakei was a flash steam plant. The first binary power plant was at Paratunka near the city of Petropavlovsk in Russia in 1967 with a capacity of $670 \mathrm{~kW}$.

Besides geothermal for electricity generation, in 1946 the first geothermal heat pump was developed at The Ohio State University in US for residential use followed in the same year by the first ground-source geothermal heat pump installed at Commonwealth Building in Portland, Oregon. Many countries around the world continue to develop geothermal energy resources for heat and electricity although at a low pace.

In a shift from use of high temperature geothermal, the first pilot plants by Ormat were developed in the early 1980s, targeting low-temperature geothermal resources using the ORC binary technology. This system enabled the commercial exploitation of resources otherwise not exploitable and as a competitive solution also for certain medium- to high-temperature geothermal resources. The Kalina cycle, utilizing a mixture of water and ammonia was latter developed with a theoretically greater thermodynamic performance, though the system was complex and had related technical difficulties in a commercial application making organic Rankine system more popular. Consequently, geothermal binary technology nowadays is substantially synonymous with ORC. (Di Pippo, 2012; Lund, 2007; Rinkesh, n.d.; Chiasson, 2016).

\subsection{Nature of Geothermal Energy}

As a heat engine, the earth is cooled heating of the lower crust and mantle by thermal decay of radioactive isotopes. As a result of this, the deeper beneath the surface, the hotter the temperature is. The challenge is that rate of temperature increase with depth over most of the regions of the earth is too low to for use to do useful work. However, some parts of the crust have significantly high heat flow rates and these can provide heat energy at depths that can be economically exploited using several existing technologies (World Energy Council, 2016).

Geothermal energy is a well-established and relatively mature form of commercial renewable energy characterized by a high load factor, which means that its installed capacity produces significantly more electricity during a year than other sources like wind and solar power plants. Geothermal power plants provide stable production output, unaffected by weather or climate, resulting in high capacity factors ranging from $60 \%$ to $90 \%$ which is ideal for making the technology suitable for base load electricity production.

Geothermal energy has significant potential and Bradley (2016) argues that although geographical limitations exist on where geothermal energy technologies can be used to their full potential, the world will realize powerful as well as efficient geothermal power plants developed in the future. Bradley further observes that the use of geothermal energy, together with solar, wind and hydroelectricity, has a potential to reduce dependence on non-renewable energy sources such as coal, oil and gas, as such, it is an ideal solution to the problem of greenhouse gas emissions and the problem of global warming.

\subsection{STATEMENT OF THE PROBLEM}

Geothermal energy is renewable and has less carbon effect hence its increased use will lead to reduced development and use of fossil fuels in power generation and mitigate against global warming since most of the global contribution to greenhouse gases emissions come from power stations which is currently dominated by fossil fuels like coal, natural gas and diesel power plants which are polluting and non-renewable. The challenge we have is that development of geothermal power plants is expensive and takes very long time to realize. There is need to speed up geothermal electricity development from the current 3-4\% annual growth 
with several regions and countries with under developed or unexploited geothermal resources like South America, Africa including Ethiopia and Tanzania, Russia in the Kamchatka peninsula, and several areas in China. The underdevelopment is due to difficulties in accessing this resource, investment, and technical challenges which include location of the geothermal resources. In as far as resource exploration is concerned, it is necessary to establish the state of resource but presently, the use of chemical geothermometers is the only feasible technique. Additionally Drilling is expensive, yet you are not assured of success and therefore development of geophysical methods to resolve this problem is highly desirable as it could significantly reduce the cost of geothermal energy development while accurate estimation before drilling will significantly reduce costs. As global concerns over global warming gather momentum, geothermal energy offers a solution, but the rate of resource exploitation is too low with very long gestation periods and generally huge costs are involved (Bradly,2016; Di Pippo, 2012; Lund, 2007; Rinkesh, n.d.; Chiasson, 2016).

Therefore there is need to identify problems and develop solutions to enable faster geothermal electricity development, reduce costs and accelerate growth and efficiency. This research seeks answers to these problems and recommendations to help in faster realization of geothermal electricity.

\subsection{Global Overview of Geothermal Energy and Growth}

\subsection{Global Overview}

The technical potential of geothermal energy is significant with about 118 Exajoulesj/year to a depth of $3 \mathrm{~km}$ and 1,109 Exajoules per year (Ej/year) to a depth of $10 \mathrm{KM}$ for electricity production (Goldstein, 2011). According to Broomley (2010) and Lund, et al. (2010), geothermal energy supplied baseload electricity in 24 countries with installed capacity of 10.7 gigawatts of electricity $(\mathrm{GWe})$ at global average capacity factor of $71 \%$ with newer plants yielding capacity factor of over $90 \%$ while accounting for $10 \%$ to $30 \%$ electricity demand in six countries in 2010 . For direct applications, geothermal energy supplied direct heat applications in 78 countries accounting for 50.6 gigawatts thermal energy $\left(\mathrm{GW}_{\text {th }}\right)$ spread over district or space heating, cooling and geothermal heat pumps.

World electricity generation from geothermal in 2014 totaled $73.3 \mathrm{TWhr}$, spread among 24 countries while in 2015, total power output totaled $75 \mathrm{TWhr}$ which is about $0.3 \%$ of global electricity production in 2015 . The Asia Pacific region generated the most electricity accounting for $40 \%$ generation followed by North America generating 30\%. Despite the high capacity growth among developing nations in recent years, OECD countries still account for over $63 \%$ of the global output (World Energy Council, 2016, IRENA 2017). The capacity continues to grow yearly and according to IRENA (2017), global geothermal power capacity by the end of 2016 totaled 12.7 gigawatts (GW), with annual electricity generation reaching 80.9 terawatt-hours (TWhr). According to the Geothermal Energy Association (2016), the global geothermal industry is expected to reach about $18.4 \mathrm{GW}$ by 2021. On his part Ritcher (2017) observed that in 2017, 24 countries around the world produced geothermal power with a combined installed power generation capacity of 13,270 MW withy about 14,165 MW in development.

Geothermal energy use is projected to grow globally, with rapid growth in countries like Indonesia, the Philippines, and Kenya, which have significant geothermal resources. Major players in geothermal power development include investment banks, who are teaming up with countries with untapped geothermal energy like Chile in South America to diversify their national energy mix and meet the Paris Climate Agreement goals of lowering the global output of $\mathrm{CO}_{2}$. Some countries like Kenya in Africa and Indonesia in Asia have set frameworks in place ensuring that a significant portion of the electricity generation is from geothermal energy (Nelson, 2017). These shows that if countries make deliberate decisions to go green, likelihoods of developing geothermal resources are high as demonstrated by successes in Kenya and Indonesia.

Geothermal power operates higher load factor than wind or solar and this is mainly because of its continuous availability free from seasonal variability, so geothermal energy produces significantly more electricity per MW of installed capacity compared to equivalent plants with same capacity from other sources of energy. However due to geological conditions required for geothermal power, development has been concentrated in a relatively small number of countries around the world.

\subsection{Geothermal Growth and Potential}

Given the natural heat storage capacity, geothermal energy is suitable for supply of both baseload-electric power and for heating and cooling applications in buildings (Goldstein, 2011). It is noted that geothermal power generation grew by $3.6 \%$ in 2016 while overall the geothermal share of global power generation remains very small $(0.3 \%)$, but in certain countries it plays a significant role, for example, Kenya (44\% of power), Iceland (27\%), El Salvador (26\%), and New Zealand (18\%) of electricity installed capacity. These statistics show extremely encouraging commitment by countries especially Kenya to develop geothermal power and hence the need to expand research into new ways of economically generating power from geothermal (WEC, 2017; BP, 2016). 
In 2016, global geothermal power generation stood at an estimated $84 \mathrm{TWhr}$, while the cumulative capacity reached just over $13 \mathrm{GW}$. Global geothermal power capacity is expected to rise to almost $17 \mathrm{GW}$ by 2021 , with the biggest capacity additions expected in Indonesia, Turkey, the Philippines and Mexico (IEA, 2017; BP, 2017; Ritcher 2017).

\subsection{GEOTHERMAL RESOURCE CAPACITIES AND DEVELOPMENT}

\subsection{Technical Potential of Geothermal Energy}

\subsubsection{The Energy Content of the earth}

The earth has been radiating heat energy for close to 4.5 billion years from its center. It is estimated that some $6437.4 \mathrm{KM}$ (4,000 miles) deep in the crust, the temperature is around $5,500^{\circ} \mathrm{C}\left(9937^{\circ} \mathrm{F}\right)$ with scientists estimating that 42 million $\mathrm{MW}$ of power flows from the earth's interior mainly through conduction. Figure 1 shows the temperature distribution in the earth (Geothermal Association, 2014).

The energy content of domestic geothermal resources to a depth of $3 \mathrm{~km}$ is estimated to be 3 million quads of heat energy, equivalent to a 30,000 years supply of energy at the current rate of consumption by the United States. However, it is not technically possible to recover the entire resource base and most of the geothermal resources are at a low temperature. There is need for new low- temperature electricity generation technologies to significantly expand the geothermal resources that can be developed economically today (Di Pippo, 2017). Compared to fossil fuels, Shere (2013) asserts that geothermal power has considerable potential for growth with amount of heat within 10,000 metres of the earth's surface estimated to contain 50,000 times more energy than all oil and gas resources available worldwide.

According to Karytsas and Mendrinos (2013) the heat content of the earth crust is estimated to at 10, 775, 600 billion TOE corresponding to 10,500 times the known global fossil fuel reserves estimated at 422 billion TOE coal, 234 billion TOE oil and 188 billion TOE natural gas. Geothermal resources in areas with magmatic intrusions located at boundaries of lithosphere plates have about 327, 360 billion TOE or 400 times the global fossil fuel reserves. (Geothermal Association, 2014).

\section{4..2. The Earths Thernmal Gradient}

The geothermal gradient refers to the increase in the temperature with depth in the earth's crust with normal average geothermal gradient is 2.5 to $30^{\circ} \mathrm{C} / \mathrm{km}$. (Dickson \& Fanelli, 2003; Lund, 2009). According to Lund (2009), it is feasible to exploit geothermal resources where temperature gradient is above the average. According to Goldstein, et al. (2010) the global average of land temperature is $15^{\circ} \mathrm{C}$. Therefore with an approximate global geothermal temperature gradient for land areas far from volcanic settings of about $30^{\circ} \mathrm{C} / \mathrm{km}$, high temperatures greater than $180^{\circ} \mathrm{C}$ can be obtained at an average depth of $5.5 \mathrm{~km}$ below the surface of the earth's surface.

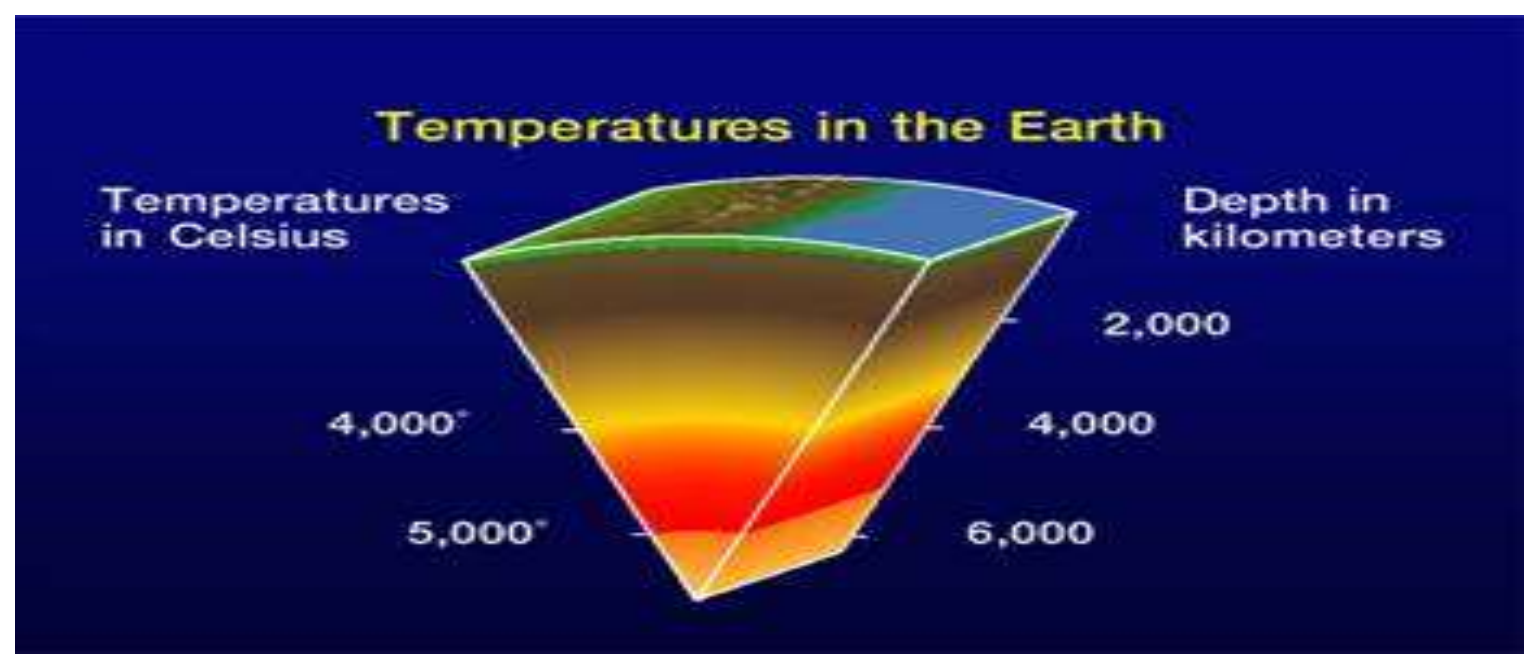

Figure 1: Temperature distribution in the earth.

Adopted from Geothermal Energy association (2014).Figure 1 shows that deep in the earth's crust, the temperature is greater than $5,500^{\circ} \mathrm{C}$ at about $6000 \mathrm{Km}$ underneath.

\subsection{Global Geothermal Electricity Generation Capacity and Potential}

The world geothermal generation capacity has been growing at a rate of 3\% to $4 \%$ per year, generally proportionate with the rate of world economic growth for the last decade. Most of this growth took place in Kenya (392 MWe), the USA (352 MWe), New Zealand (400 MWe), and Turkey (306 MWe) which together account for $60 \%$ of world geothermal electricity capacity growth. Economic growth globally coupled with high fossil fuel prices provided ground and incentives for geothermal electricity 
capacity investment with committed projects expected to add about 2,000 MWe (a 16\% capacity increase) between January 2015 and December 2018. Most of this new capacity was installed in Indonesia (636 MWe), Turkey (298 MWe) and Kenya (255 MWe). Additional geothermal generation is expected to extend to Iran, Croatia, Chile, and Honduras, an indicator that geothermal has proved attractive and is worth investing in. (World Energy Council, 2016). These shows global commitment to growth of geothermal power generation especially amongst non-oil producing countries around the world.

In 1999, $8 \mathrm{GWe}$ of electrical generating plant worldwide was powered by geothermal heat. Geothermal sources generated 49 terawatt hours of virtually pollution-free power that year (Williams, et.al. 2001) while according to BP (2017), geothermal electricity capacity grew by $3.4 \%$ (440 MW) in 2016, to reach $13.4 \mathrm{GW}$ with the largest additions to capacity taking place in Indonesia (190 MW) and Turkey (150 MW). BP further observed that the United States has the largest geothermal capacity with 3.6 GW (27\% of the world total), followed by the Philippines (1.9 GW), Indonesia (1.6 GW) and New Zealand (1.0 GW).

Whereas the US continues to lead the world in geothermal electricity generation with an estimated total installed capacity of just under 3,400 MW and 3,591 MW in 2018, Indonesia has improved significantly to overtake Philippines as the world's second largest producer of geothermal electricity while Italy is currently the fourth largest producer of Geothermal electricity with New Zealand being the fifth based on 2015 statistics (Bradley, 2016). It is also worth noting that Indonesia has the largest global potential of geothermal energy although the country is highly dependent on fossil fuels mainly coal, as its primary source of electricity generation (World Bank, 2017). It is therefore expected that Indonesia should play a leading role in development of geothermal electricity production to substitute coal and other fossil fuels which are major contributors of greenhouse gas emissions.

In 2017, global geothermal power generation stood at an estimated $84.8 \mathrm{TWhr}$, with total capacity of 14 GW. Global geothermal power capacity is expected to rise to just over17 GW by 2023 , with the biggest capacity additions expected in Indonesia, Kenya, Philippines and Turkey (International Energy Agency, 2017). In October 2018, global geothermal capacity reached 14,369 MW after new additions capacity s in Turkey and New Zealand (Richter, 2018).

According to Ritcher (2019) global geothermal capacity reached 14.6 GWe by the end of 2018 with 587 MW new capacity in 2018 mainly coming from Turkey at 294, MW, Indonesia at 139 MW, US at 48 MW, New Zealand at 25 MW, Iceland 45 at MW, Italy 134 at MW, Croatia at $18 \mathrm{MW}$, China at $15 \mathrm{MW}$, Germany at $3 \mathrm{MW}$ and others contributing $1 \mathrm{MW}$. A review of geothermal capacity growth for the period between 2009-2018 showed the countries that have registered greatest growth as follows; Turkey (1317 MW), Indonesia (956 MW), US (599), Kenya (509 MW), New Zealand (421MW), Iceland (180 MW), Italy (134 MW) and Others $(220 \mathrm{MW})$. These demonstrates that there is commitment by countries across the globe to promote geothermal power development.

Economically geothermal energy market is a signigficant contributor to the gross domestic product of many countries. According to Karytsas and Mendrinos (2013) the global geothermal power market was about 11.6 billion euro in 2012 corresponding to about 11,456 MWe of installed capacity and 71,997 GWhe and 7.2 billion euro in investments. The geothermal steam turbines market is dominated by six major manufacturers. This shows that the geothermal technology market is competitive though with relatively fewer players.

Therefore geothermal energy development does not only provide substitution for fossil fuels in electricity generation, but also has significant role to play in economic development by contributing to the gross domestic product.

\subsection{Geothermal Capacity and Growth for 2017/2018}

As at the end of 2018, the 10 leading countries in installed geothermal electricity capacity were as follows in table 1.

Table 1: Geothermal capacity growth for year 2017/2018 
International Journal of Advances in Scientific Research and Engineering (ijasre), Vol 5 (8), August-2019

\begin{tabular}{|l|l|l|}
\hline RANK & COUNTRY & $\begin{array}{l}\text { INSTALLED CAPACITY } \\
(\mathbf{M W})\end{array}$ \\
\hline 1 & United State & 3,639 \\
\hline 2 & Indonesia & 1,948 \\
\hline 3 & Philippines & 1,868 \\
\hline 4 & Turkey & 1,347 \\
\hline 5 & New Zealand & 1,005 \\
\hline 6 & Mexico & 951 \\
\hline 7 & Italy & 944 \\
\hline 8 & Iceland & 755 \\
\hline 9 & Kenya & 676 \\
\hline 10 & Japan & 542 \\
\hline 11 & Other Countries & 925 \\
\hline TOTAL GLOBAL CAPACITY & $\mathbf{1 4 , 6 0 0}$ \\
\hline
\end{tabular}

Table1 shows production capacity of 10 leading countries with US, Indonesia and the Philippines being top three while Kenya and japan close the top ten at position 9 and 10 in terms of geothermal electricity generation capacity for the year 2018. Further analysis shows that the US leads the world in new geothermal power development followed by Asian countries of Indonesia and Philippines while Kenya leads Africa in geothermal power capacity and generation as per data for the year 2018. Other countries need to identify the initiatives put in place by these countries to accelerate growth of geothermal energy and electricity.

\subsection{Growth in Geothermal generation capacity between 1990 and 2018}

The development of geothermal generation capacity between 1960 and 2018 is summarized in the table below in table 2 bellow.

Table 2. Geothermal energy capacity and growth

\begin{tabular}{|l|l|l|l|l|}
\hline YEAR & $\begin{array}{l}\text { INSTALLED } \\
\text { CAPACITY } \\
\text { (GWe) }\end{array}$ & $\begin{array}{l}\text { ELECTRICITY } \\
\text { PRODUCTION } \\
\text { (GWHr/year) }\end{array}$ & $\begin{array}{l}\text { CAPACITY } \\
\text { FACTOR } \\
\text { (PERCENT) }\end{array}$ \\
\hline 1 & 1960 & 0.386 & 2,600 & 77 \\
\hline 2 & 1995 & 6.8 & 38,035 & 64 \\
\hline 3 & 1999 & 7.979 & 49,000 & 70 \\
\hline 4 & 2000 & 8.0 & 49,261 & 71 \\
\hline 5 & 2005 & 8.9 & 56,786 & 73 \\
\hline 6 & 2010 & 10.7 & 67,246 & 71 \\
\hline 7 & 2014 & 11.62 & 73,300 & 72 \\
\hline 8 & 2015 & 12.60 & 73,549 & 75 \\
\hline 9 & 2017 & 13.28 & 84,800 & 73 \\
\hline 10 & 2018 & 14.6 & - & - \\
\hline
\end{tabular}

(-) means data not accessed by time of publication.

From table 2 it is noted that geothermal electricity capacity has shown growth from $6.8 \mathrm{GW}$ in 1998 to $14.6 \mathrm{GW}$ in 2018, representing growth of $115 \%$ in capacity. The global average of capacity factor which is the ration of average load to plant capacity was lowest in 1995 reflecting operational challenges for that year but for all other years between 1960 and 2017, the capacity factor has been above $70 \%$ showing above average loading and use of operating geothermal power plants globally, a necessary factor for use as base load power plants. 


\subsection{Global Geothermal Potential}

Matek (2016) observed that there are 200GWe of conventional hydrothermal potential globally based on existing technology. This suggests that only 6-7\% of global geothermal power potential has been so far tapped. El Salvador plans to have $40 \%$ of its electricity from geothermal while Kenya generates roughly $50 \%$ of its electricity from geothermal. This shows that Kenya has the largest contribution to grid power from geothermal globally.

\subsection{SUB-SURFACE TECHNOLOGY AND GEOTHERMAL ENERGY}

\subsection{Technical Challenges for geothermal development}

Discovering and exploiting subsurface energy resources while mitigating their impact constitute a major technical and sociopolitical challenge. Therefore, advances in subsurface technology will enhance geothermal energy development (US Energy Department, 2017).

According to the US Energy Department (2017) the subsurface challenges are;

i.) Discovering, Characterizing, and Predicting

ii.) Accurately characterizing the subsurface using integrated geophysical and geochemical technologies

iii.) Quantitatively inferring subsurface evolution under current and future engineered conditions.

iv.) Finding viable, low-risk geothermal resources

v.) Challenges of accessing geothermal resources in terms of cost. Important is to develop safe, cost-effective drilling and completions with properly managed wellbore integrity

vi.) Engineering Challenges in the form of general difficulty in creating or constructing desired subsurface conditions in challenging high-pressure and high-temperature environments like supercritical geothermal resources.

vii.) Challenge of sustaining the resources in terms of maintaining optimal subsurface conditions over multi-decadal or longer time frames through complex geothermal system evolution.

viii.) Challenges of monitoring the resources in form of improving observational methods to advance the understanding of the complex geothermal systems.

Some geothermal fields have a challenge of supplying steam for stable operation due to the depletion of the geothermal fluid, which can be caused by, cooling, vaporization and acidification of the geothermal field. As a solution there is need to stabilize the production of steam and hot water through y better accuracy in evaluation of the geothermal fluid characteristics and recharging water to the geothermal reservoir via the reinjection wells (Tosha, Shimada, \& Nakashima, 2017).

\subsection{Developments in Subsurface Technology}

\subsection{Seismic reflective analysis}

Seismic reflection is one of the most precise methods to detect geological structure. The reflection survey is commonly adapted to find out anticline structure for oil and gas exploration. Seismic reflection data were collected at several geothermal fields in order to detect fractures associated with geothermal resources in Japan. However, faults were not always detected clearly by the reflection data generated by the process.

\subsection{Electromagnetic Survey (EM)}

According to Ugwu \& Nwosu (2009) the electromagnetic methods work by measuring the electrical resistivity of the earth. EM methods make use of the response of the ground to the propagation of electromagnetic field. The response varies according to the conductivity of the ground (in $\mathrm{S} / \mathrm{m}$ ).

Applications of electromagnetic surveys include;

i. Mineral exploration and hence development.

ii. Mineral resource evaluation

iii. Groundwater surveys and analysis

iv. Mapping contaminant plumes in the fields

v. Geothermal resource investigations

vi. Contaminated land mapping

vii. Landfill surveys

viii. Detection of geological and artificial cavities

ix. Identification and location of geological faults, etc.

x. Geological mapping

xi. Permafrost mapping, etc.

The advantages of electromagnetic survey are 
i. The main advantage of the EM methods is that they do not require direct contact with the ground as in the case of DC electrical methods. Therefore, the Measurements can be carried out in a faster way than the DC measurements.

ii. The range of EM applications is large and dependent upon the type of equipment These shows significant benefits from electromagnetic survey techniques and wider applications beyond geothermal resource mapping and development.

\subsection{Management of Technology in Geothermal Reservoir Characteristics}

Some geothermal fields encounter trouble in generating steam needed for stable operation due to the depletion of the geothermal fluid, which leads to vaporization, cooling, and acidification of the reservoir. The depletion of the fluid makes sometimes a severe damage of the operation as the pressure at the inlet of the turbine becomes lower than the limitation. There is need to stabilize the production of subsurface geothermal steam and hot water by not only improving accuracy in evaluation of the behavior of the geothermal fluid, but recharging water to the geothermal reservoir (Okabe, et al., 2015).

The geothermal reservoir and production wells are connected synergetic flow systems with radially-inward Darcy flow toward the well in the reservoir, and a turbulent up flow through the ducting, piping or tubing. The pressure losses of the two flows are added cumulatively. The pressure energy of the undisturbed reservoir as able to sustain this motion and so provides the required energy against the pressure losses and for lifting the fluid to the surface and hence for resource exploitation. The thermal lift together with the lifting force of the dissolved gases maintains the operation of the free flowing well. Two-phase flow develops in the upper section of the geothermal well. Several forms of vertical two-phase flows are studied. The process of well flashing also produces similar lifting effects if the temperature of water produced is high enough. These phenomena enables smooth and continuous operation of geothermal wells and hence electricity production.

\subsubsection{Geothermal reservoir layers}

Many geothermal reservoirs have chemically and physically distinct layers which can significantly effect on resource capacity. Some layers can be characterized by distinct reservoir rocks, mineral alteration, fluid chemistry, and temperature. In Kizildere, Turkey, preproduction chemistry of the deep reservoir indicated higher gas and higher geothermometers than the intermediate reservoir, which had been produced for many years, indicating limited circulation between layers in the natural state. In other geothermal areas such as Los Azufres and Cerro Prieto in Mexico, layers are distinguished by gas concentrations and enthalpy, and appear to be well connected. With geochemical monitoring, relative changes in and communication between layers with distinct geochemistry can be monitored during reservoir production and injection. These can influence the life and performance of geothermal wells (Ungemach, Antics\& Papachristou, 2005).

Therefore proper geothermal reservoir engineering and management is critical for sustainable use of geothermal resource and continuous electricity generation (Lund, 2009; Okabe, et al., 2015). Therefore accurate or clear understanding of the nature of geothermal reservoir layers is important in sustainable resource planning and exploitation.

\subsection{Subsurface Technologies for Developing Geothermal Energy}

A number of technologies have been developed to improve project cycle management and developing for all major operations and activities in geothermal project development. This is summarized in table 3 bellow.

Table 3: The technology development in Geothermal Resources

\begin{tabular}{|l|l|l|}
\hline & ACTIVITIES/OPERATIONS & \\
\hline 1 & Survey & $\begin{array}{l}\text { Gravity survey, geological survey, geochemical survey, thermal } \\
\text { alteration survey, surveys in airplanes and satellite. }\end{array}$ \\
\hline 2 & Exploration & $\begin{array}{l}\text { Geophysical exploration using electric, magnetic, and seismic } \\
\text { methods, surface exploration and exploration wells. }\end{array}$ \\
\hline 3 & Performance Prediction & Geological and hydrological modelling \\
\hline 4 & Drilling & $\begin{array}{l}\text { Directional drilling, highly deviated drilling, measurement while } \\
\text { drilling (MWD), Down Hole Motor technologies (DHM) }\end{array}$ \\
\hline 5 & Evaluation/Assessment & $\begin{array}{l}\text { Resource evaluation, Environmental Impact Assessment, Social } \\
\text { impact assessment, Economic assessments, Risk assessments }\end{array}$ \\
\hline 6 & Production & $\begin{array}{l}\text { Well simulation, scale inhibitor, steam production from acid } \\
\text { geothermal fluid cultivation }\end{array}$ \\
\hline 7 & Monitoring & $\begin{array}{l}\text { Seismic, monitoring, environmental monitoring, land elevation } \\
\text { monitoring. }\end{array}$ \\
\hline
\end{tabular}


Table 3 shows that the main stages in geothermal project cycle development, namely survey, exploration, prediction of performance, drilling, evaluation, production and monitoring of performance have unique opportunities for success through unique technology.

\subsection{GEOTHERMAL, SYSTEMS, RESOURCES AND CHARACTERISTICS \\ 6.1 Geothermal Systems}

A geothermal system is made up of three main elements namely; a heat source, a reservoir and a fluid, which is the carrier of the heat. The heat source can be either a very high-temperature (greater than $600{ }^{\circ} \mathrm{C}$ ) magmatic intrusion that has reached relatively shallow depths (5 to $10 \mathrm{~km}$ ) or, as in certain low-temperature systems.

\subsubsection{Geothermal Reservoir}

Geothermal reservoir is a volume of hot permeable rocks from which the circulating fluids extract heat. The reservoir is generally overlaid with a cover of impermeable rocks and connected to a surficial recharge area through which the meteoric waters can replace or partly replace the fluids that escape from the reservoir through springs or are extracted by boreholes. The geothermal fluid is water, in most of the cases meteoric water, in the liquid or vapor phase, depending on its temperature and pressure. This water often carries with its chemicals and gases such as Carbon dioxide $\left(\mathrm{CO}_{2}\right)$ and $\mathrm{Hydrogen}$ sulfide $\left(\mathrm{H}_{2} \mathrm{~S}\right)$ (Dickson \& Fanelli, 2003).

\subsubsection{Heat Source}

This is the origin of heat in the geothermal system. It can be high temperature magmatic intrusions, radioactivity or low temperature system getting the heat from deep underground through conduction or convection. Thermal energy generated from radioactive sources depends on both presence and level of radioisotopes that may include Uranium-238, Uranium -235 and lithium -232 (Berrizbeitia, 2014).

\subsection{3. . Geothermal Fluid}

This is the media through which heat is conveyed to the surface and is mainly meteoric water in form of liquid, vapor or mixture of liquid and vapor. Geothermal fluid often contains gases and dissolved minerals or chemical like Carbon Dioxide $\left(\mathrm{CO}_{2}\right)$, hydrogen sulphite $\left(\mathrm{H}_{2} \mathrm{~S}\right)$.

\subsection{GEOTHERMAL RESOURCES}

According to Muffler and Catldi (1978), a geothermal resource is one that is accessible. A geothermal resource constitutes quantity of stored energy between the earth surface and specific depth in the earth's crust underneath a specified area and is measured from local mean temperature. The most common criteria to classify geothermal resources is the enthalpy of geothermal fluids which is the energy carrier. It is the enthalpy that influences or determines the classification of the geothermal resource as low enthalpy, medium enthalpy or high enthalpy geothermal resource.

\subsection{Conditions for Existence of Geothermal Resource}

Geothermal energy refers to the natural heat content of the earth. There are four main conditions for the existence of a geothermal reservoir except for Hot Dry Rock (HDR) type geothermal sources.

i.) A heat source: This heat source can be a magmatic body $\left(>600^{\circ} \mathrm{C}\right)$ as well as the normal

Geothermal gradient of the earth as in the case of low-temperature geothermal sources. The temperature of the earth increases with a normal geothermal gradient of $3{ }^{\circ} \mathrm{C} / 100 \mathrm{~m}$. It is therefore possible to reach a depth to obtain a temperature of $70-100{ }^{\circ} \mathrm{C}$ with the existing drilling technology.

ii.) A heat carrier: This carrier is generally the rainwater seeping the deeper section of the earth.

iii.) A porous and permeable or fractured reservoir rock.

iv.) An impermeable caprock above the reservoir rock.

\subsection{Types of Geothermal Systems}

Geothermal sysems can be classified as convective dominated systems, which include liquid-vapour dominated hydrothermal system, conductive dominated system which include hot rock and hybrid systems which source from convection, conductio and high heat producing source e.g. magma (Goldstein, et al., 2010).

\subsection{Convective Hydrothermal Resources}

These resources occur where the Earth's heat is carried upward by convective circulation of naturally occurring hot water or steam in the earth's crust. Some high temperature convective hydrothermal resources result from deep circulation of water along fractures (Goldstein, et al. 2010).

i.) Vapor dominated reservoirs 
These systems produce steam from boiling of saline waters in low permeability rocks. Generally, these resources are fewer. Examples include The Geysers in Northern California in the USA, Larderello in Italy and Matsukawa in Japan where the steam is exploited to produce electric power. Hot water and vapor can co-exist in these reservoirs, but vapor phase is continuous phase and determines the pressure regime of the reservoir.

These systems have lower heat than hot water reservoirs, but with less problems associated with the fluid production from these reservoirs compared to hot water geothermal systems. The production mechanism of vapor-dominated reservoirs is like the natural gas reservoirs, with expansion of reservoir fluid leading to production declines. The amount of fluid produced at the abandonment is generally high at $85-90 \%$ by weight of original fluid in place in the reservoir. Most of the heat content of the reservoir resides in rock and extraction of heat from the rock in these systems is relatively low. Re-injection of produced fluid can increase the heat recovery from the reservoir by extracting more heat from the rock and effectively increases the life of the geothermal reservoir (Lund, 2009). Figure 2 below illustrates a vapor dominated geothermal system. The figure shows a vapor dominated geothermal resource which includes heat source e.g. magma, water source permeable rock

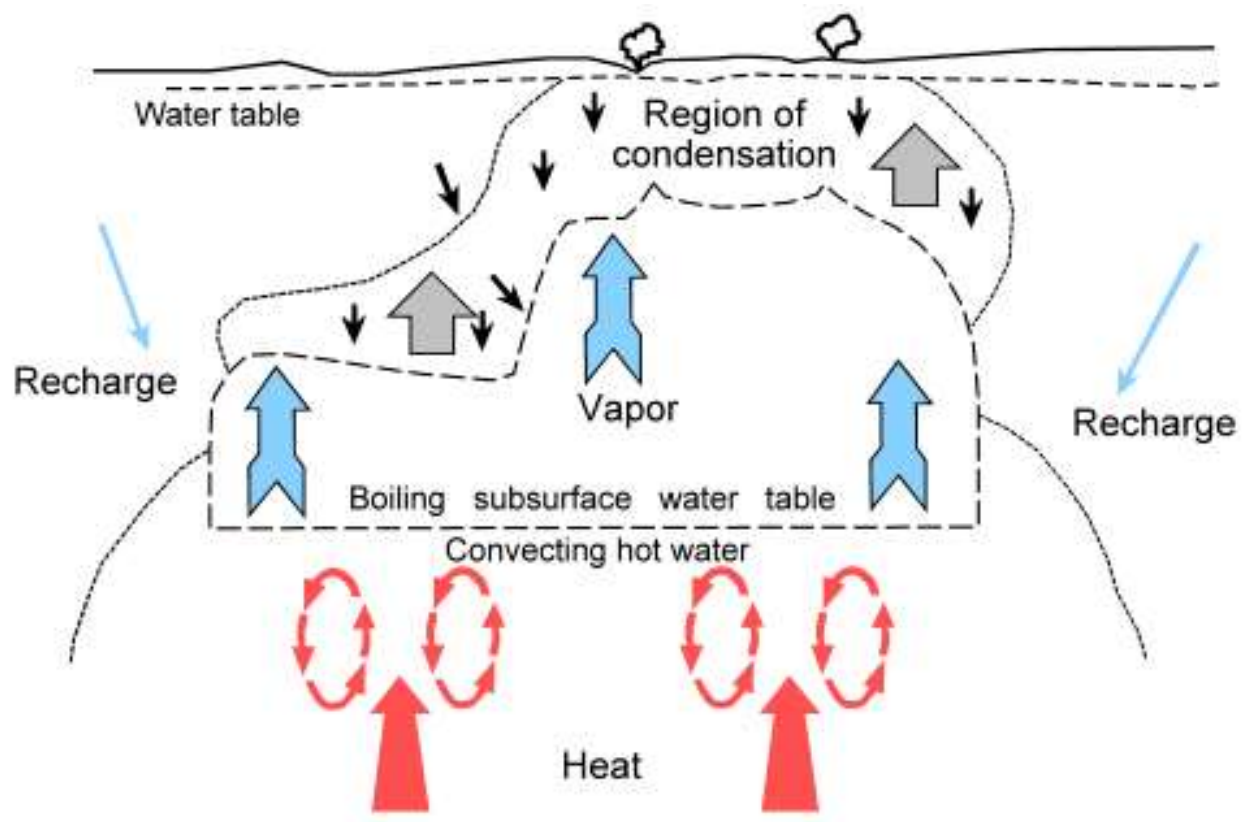

Vapor dominated geothermal system (White, et al., 1971).

Figure 2: vapor dominated reservoir

\section{ii.) Liquid/Hot water dominated reservoirs}

These are geothermal resources produced by ground water circulating to depth and ascending from buoyancy in permeable reservoirs that are a uniform temperature over large volume. There is typically an up-flow zone at the center of each convection cell, an outflow zone or plume of heated water moving laterally away from the center of the system, and a down flow zone where recharge is taking place. Surface manifestations include hot springs, fumaroles, geysers, travertine deposits, chemically altered rocks, or sometimes, no surface manifestations or blind resource (Lund, 2009).

Liquid phase is the continuous, pressure-determining phase in these reservoirs. The water within these systems is a chemical solution containing sodium, potassium, lithium, calcium, chloride, bicarbonate, sulphate, borate and silica. Wairakei in New Zealand, Cerro Prieto in Mexico, and Kizıldere in Turkey can be mentioned as the examples of liquid dominated reservoirs. The heat recovery from liquid dominated reservoirs is higher compared to heat recovery from vapor-dominated reservoirs. The main reason of the higher heat recovery is the boiling of reservoir fluid in the reservoir and/or re-injection of the produced fluid. Production problems encountered in liquid dominated reservoirs are worse compared to that of vapor dominated reservoirs (Lund, 2009). Figure 3 below illustrates a liquid or hot water dominated geothermal system. 


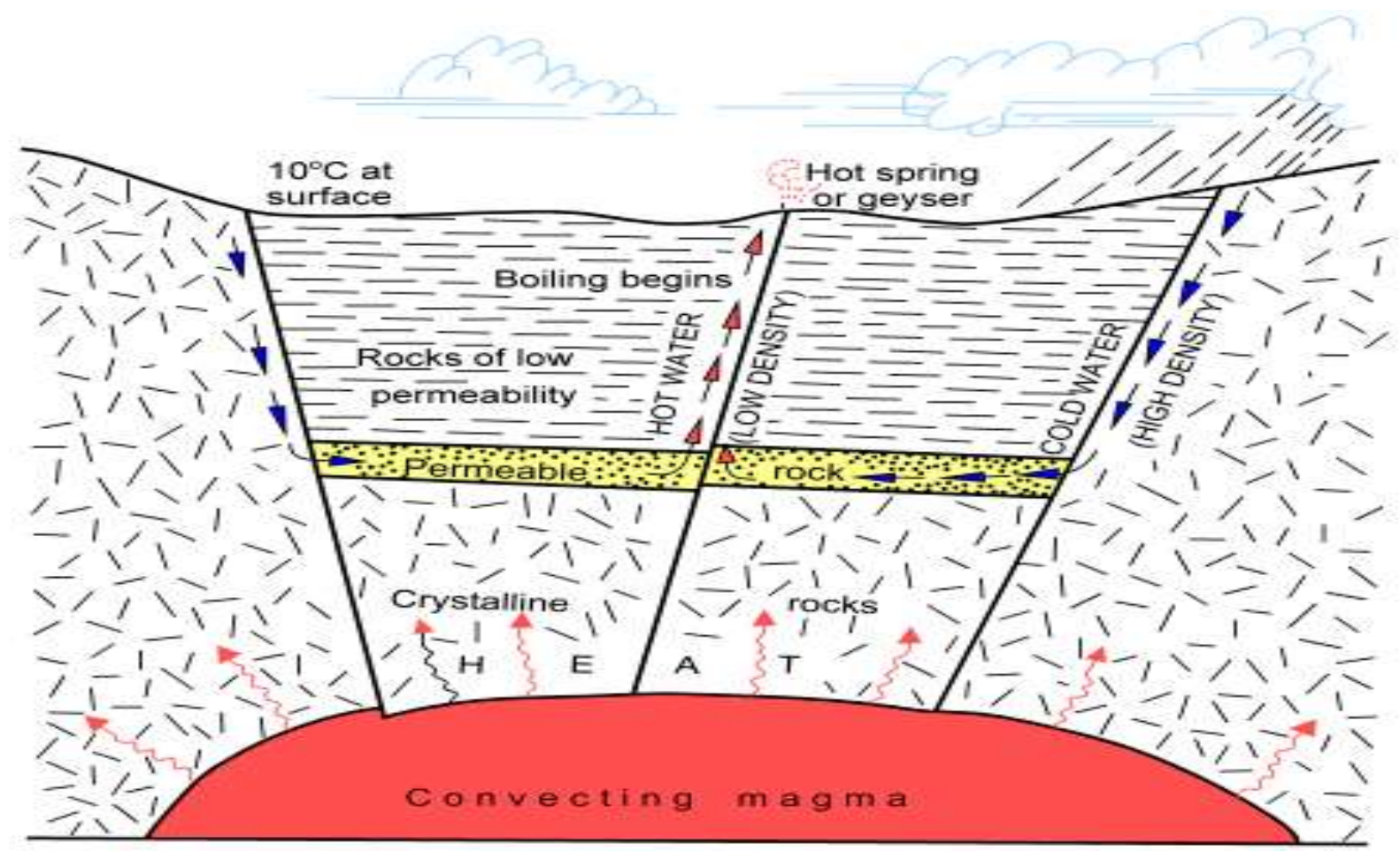

Hot water dominated geothermal system (White, et al., 1971).

Figure 3: Liquid/Hot water dominated reservoirs

Figure 3 shows main elements of liquid or hot water dominated resource which include source of heat manly magma, surface manifestations which include hot springs and geysers, low permeability rock, permeable rock structure layers of high density rocks.

\subsubsection{Geo-Pressurized Geothermal Reservoirs}

Geo-pressurized resources are methane-rich fluids often below $4.5 \mathrm{~km}$ depth are contained in reservoirs with up to $70 \mathrm{MPa}$ pressure and $150^{\circ} \mathrm{C}$ temperature. The resource takes the form of geothermal heat and the combustible natural gas that can be exploited (Williams et al., 2001).

These geothermal resources occur in basin environments where deeply buried fluids contained in permeable sedimentary rocks are warmed in a normal or enhanced geothermal gradient by virtue of their great burial depth underground. The fluids are tightly confined by surrounding impermeable rock and bear pressure much greater than hydrostatic pressure. The pressure gradient of the trapped geothermal fluid can increase with further sedimentation and can reach up to 1 psi/ft (normal hydrostatic gradient is between $0.433-0.45 \mathrm{psi} / \mathrm{ft}$ ). The temperature of these systems increases with low heat conductivity and high specific heats of the fluids. Thermal waters under high pressure in sand aquifers are the target for drilling, mainly as they contain dissolved methane which can be extracted.

Geo-pressurized geothermal resources consists of:

(1) Thermal energy

(2) Mechanical energy and,

(3) Methane gas.

The Texas and Louisiana Gulf Coast in the United States has been tested for the geothermal energy; however, due to the great depths of several kilometers, they have not proved economically viable for exploitation (Lund, 2009). Figure 4 bellow illustrates geo- pressurized geothermal resource. 


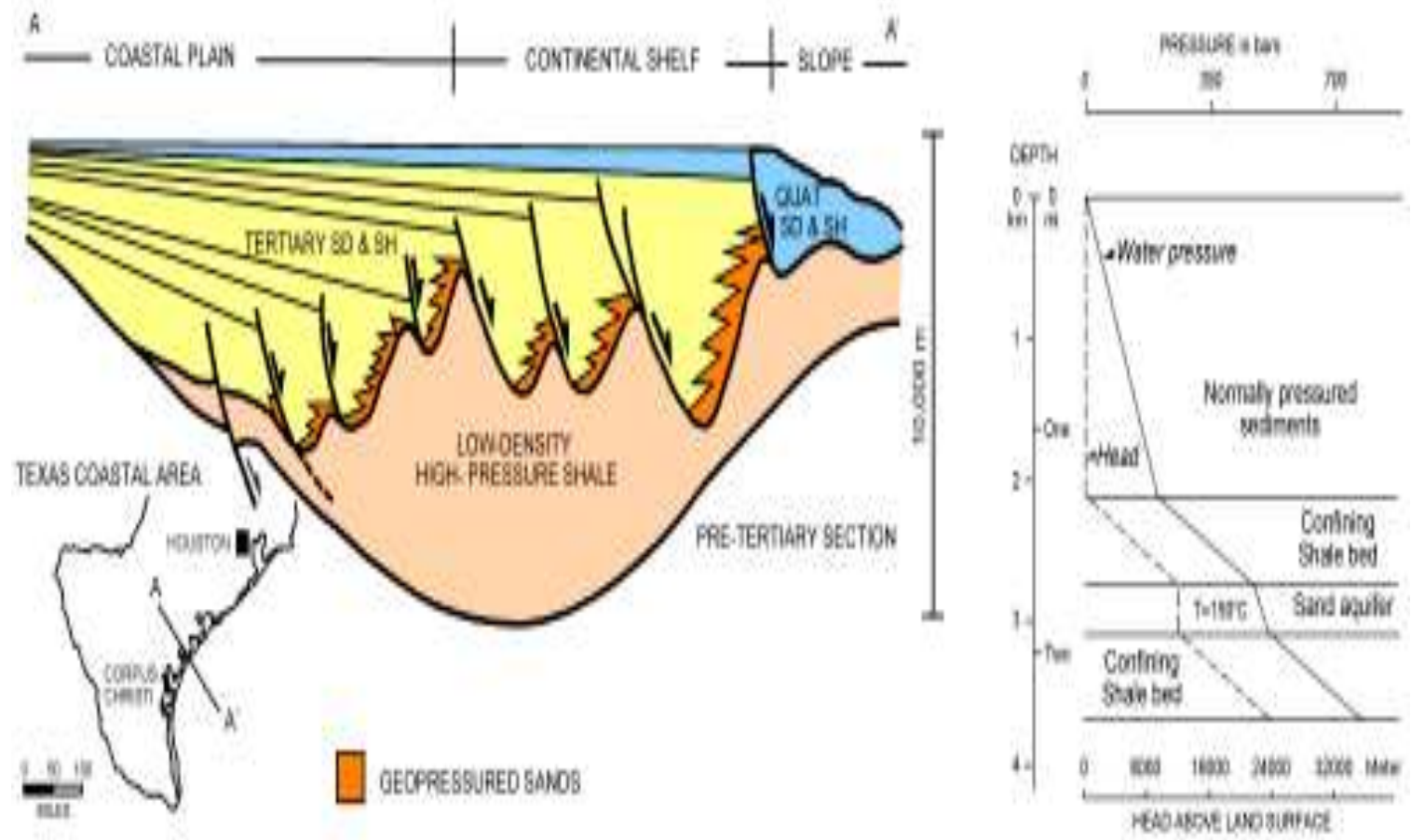

Geo-pressurized geothermal system. Adopted from (Bebout, et al., 1978).

Figure 4: Geo-pressurized geothermal reservoirs

According to Karytsas and Mendrinos (2013) geothermal of geo-pressured basins is estimated as 355.9294 billion TOE (Tons of oil equivalent) or 70 times the world total fossil fuel reserves.

Geopressured geothermal reservoirs are similar in formations to geo-pressured oil and gas reservoirs. In these resources geothermal fluid caught in a permeable rock structure, by crustal motion over millions of years with pressure rise to lithostatic pressure. Geo-pressurized resources are generally relatively deep, from $2 \mathrm{~km}$ and deeper, with thermal gradient of over $100^{\circ} \mathrm{C} / \mathrm{km}$. These reservoirs have been found in often during petroleum exploration. In some cases they are found associated with petroleum, the water which is reach with methane gas which can be exploited as a more important energy source than the heat in the water. Reservoir engineering of such a system is more like a petroleum reservoir than a hydrothermal reservoir or groundwater aquifer. The challenge with these resource as realized from Experiments conducted on existing petroleum exploration wells, in the 1980s in the U.S. Gulf Coast, in an experimental hybrid power system gave discouraging results, with operational problems high concentration of salts and high carbon dioxide. Another challenge is abnormally high pressures involved (Lund, 2009; Karytsas and Mendrinos, 2013).

Therefore, whereas geo-pressurized geothermal resources offer significant potential, challenge remains how to handle high contents of carbon dioxide, high mineral or salts content of the fluid and very high pressures associated with the resource which continue to hold back exploitation of these significant geothermal resource.

\subsubsection{Hot Dry Rock (HDR)}

These resources occur in the form of heat stored in rocks within $10 \mathrm{~km}$ of the surface from which energy cannot be economically extracted by natural hot water or steam. These hot rocks have few pore spaces, or fractures, and therefore have little or no water thus no interconnected rock permeability. To extract these heats, rocks are artificially fractured by hydraulic pressure, and cold water circulating down one well to extract the heat from the fractured rocks and then heated water extracted through another well in a closed system. Early experimental projects were undertaken at Fenton Hill (Valdes Caldera) in Northern New Mexico in the US and on Cornwall in Southwest England; however, both projects have been abandoned due to lack of funds and poor results. Current project sites include Soultz-Sous-Foret in the Rhine Graben on the French-German border, in Switzerland at Basil and Zurich, in Germany at Bad Urach, several locations in Japan, and the Cooper Basin of Australia (Tenzer, 2001; Lund, 2009).

These systems do not contain any fluid to extract and transfer the heat energy to the surface for use. The only way of utilizing these systems is to extract the heat energy of the rock by water circulation along an artificial fracture between two wells as illustrated in figure 4 below. According to Tosha, Shimada, and Nakashima (2017) fractures are created in the dry rock, where high temperature is expected with the help of seismic monitoring technology. A production well is then drilled in and connected to the injection well through the artificial fractures. Water injected into the injection well flows through the artificial fractures, absorbs heat from the hot dry rock, and goes back to the surface through the production well while extracting heat. 
If Hot Dry Rock (HDR) extraction technology becomes commercial viable, the resource base of geothermal energy will increase significantly magnitude worldwide. The main technology challenges to be addressed for HDR are drilling costs, control of water loss, and better fracture stimulation and mapping techniques. The terms hot wet rock (HWR) and Enhanced Geothermal Systems are also in use to describe research into heat extraction from low permeability geothermal systems (Williams, et al. 2001). Figure 5 bellow illustrates exploitation for hot dry rock resource.

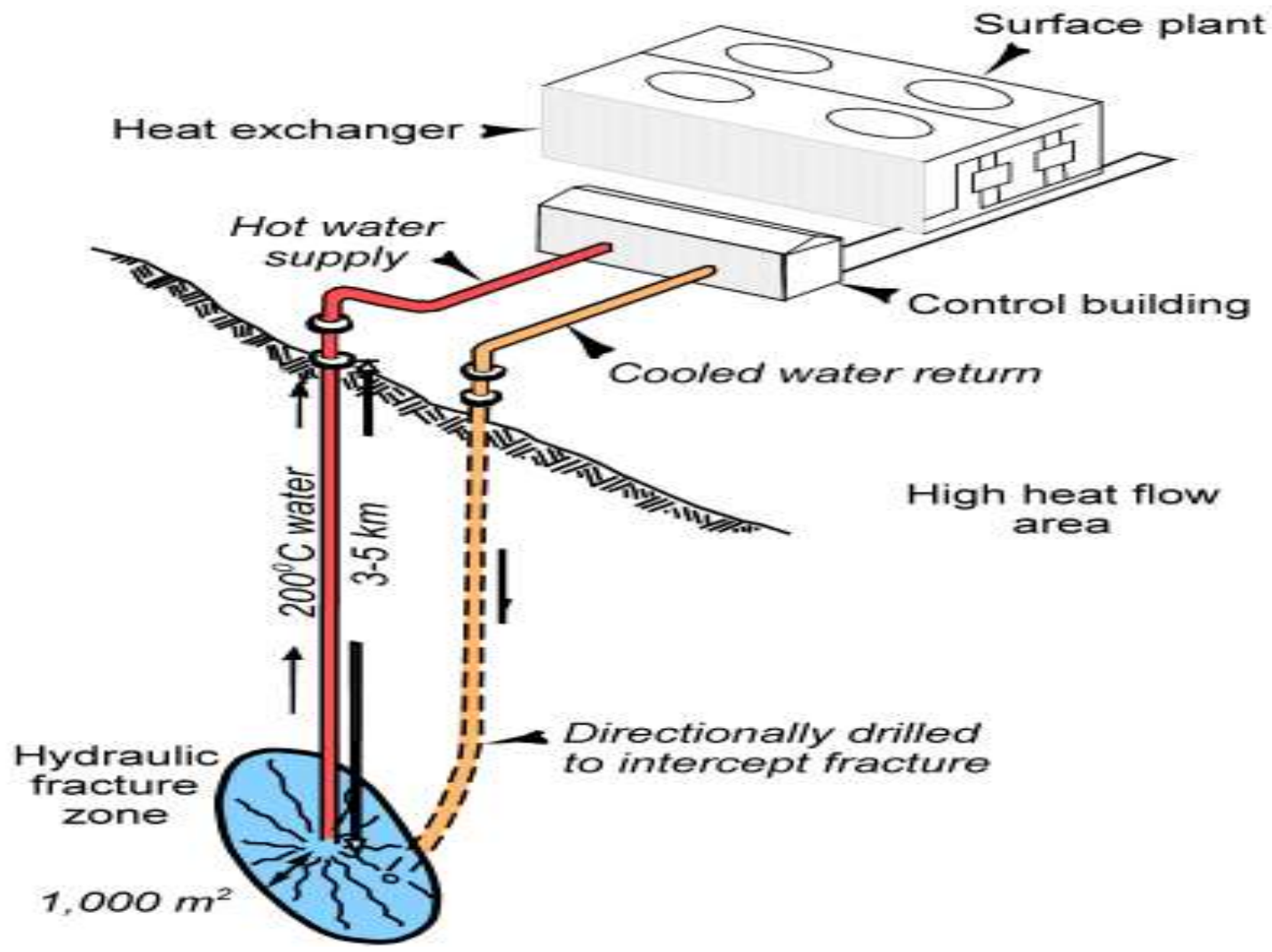

Hot dry rock exploitation (Anderson \& Lund, 1979).

Figure 5: Hot dry rock (HDR)

Quite often hot underground rock is not permeated by water and so there is no medium naturally available to bring the heat energy to the surface. Where hot rock exists close to the surface of the earth, it is possible to create a human-made hydrothermal source. This is realized by drilling into the rock and then pumping water down through an artificial. Pressurized water will cause the rock to fracture. This is similar to the process of fracking to release shale gas by creating faults and cracks through which the liquid can flow. The fracturing is made easier due to the fact that underground rock often contains natural faults and fractures through which water will force through hence easier fracturing. If a second borehole is drilled adjacent to the first, then water that has become heated as it has percolated through the rock can be extracted for power plant use. (Karytsas and Mendrinos, 2013). These demonstrates the technical feasibility of for exploitation of hot dry rocks as geothermal resources.

\subsubsection{Sedimentary Basin Geothermal Resource}

Hot sedimentary aquifer system is a geologic aquifer that overlie a radiating source of heat and heat is transferred by conduction and or convection. These geothermal resources produce higher temperature resources than the surrounding formations due to their low thermal conductivity or high heat flow or both producing geothermal gradients $>30^{\circ} \mathrm{C} / \mathrm{km}$. These resources spread over large areas. Examples include the Madison Formation of North Dakota, South Dakota, Montana and Wyoming area in the United States. In Europe these resources are found in the Pannonian Basin of Central Europe where it has been used extensively in Hungary (Tenzer, 2001; Lund, 2009). Figure 6 below illustrates sedimentary basin geothermal resources. Figure 6 bellow is an illustration of sedimentary geothermal resource. 


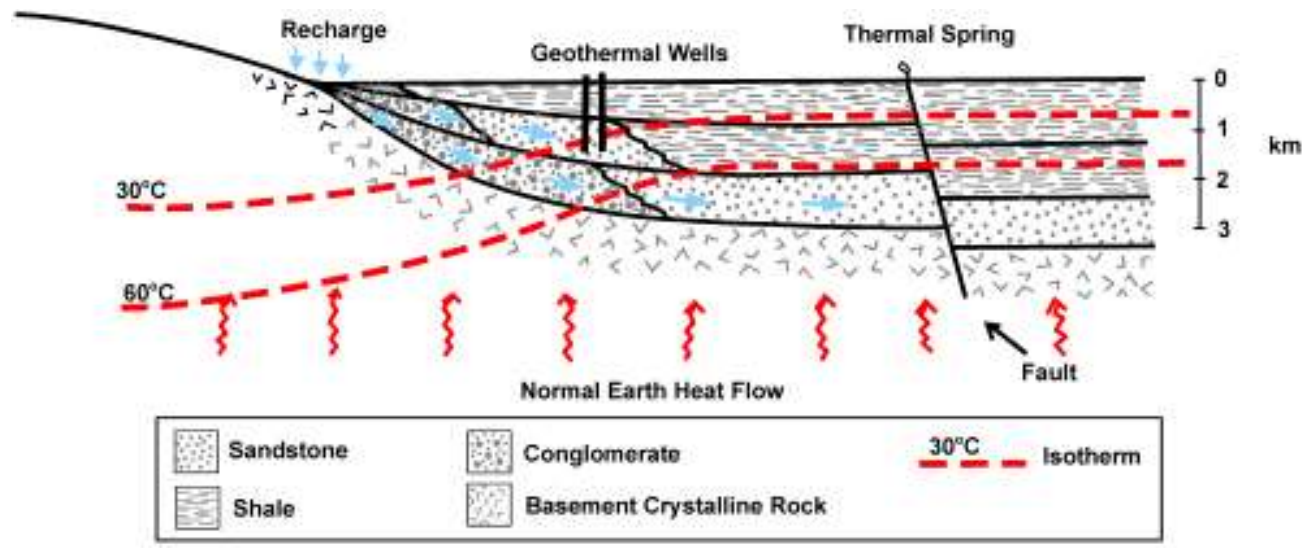

Sedimentary basin resources (Anderson \& Lund, 1979).

Figure 6: Sedimentary Basin Geothermal Resource

\subsubsection{Radiogenic Resources}

These geothermal resources are found in areas where granitic intrusions are near the earth's surface causing heating up of the local groundwater from the decay of radioactive materials like thorium, potassium and uranium. This localized heating increases the normal geothermal gradient providing hot water at economical drilling depths for applications like space heating and other low to medium temperature applications. These resources are illustrated in figure 7 below.

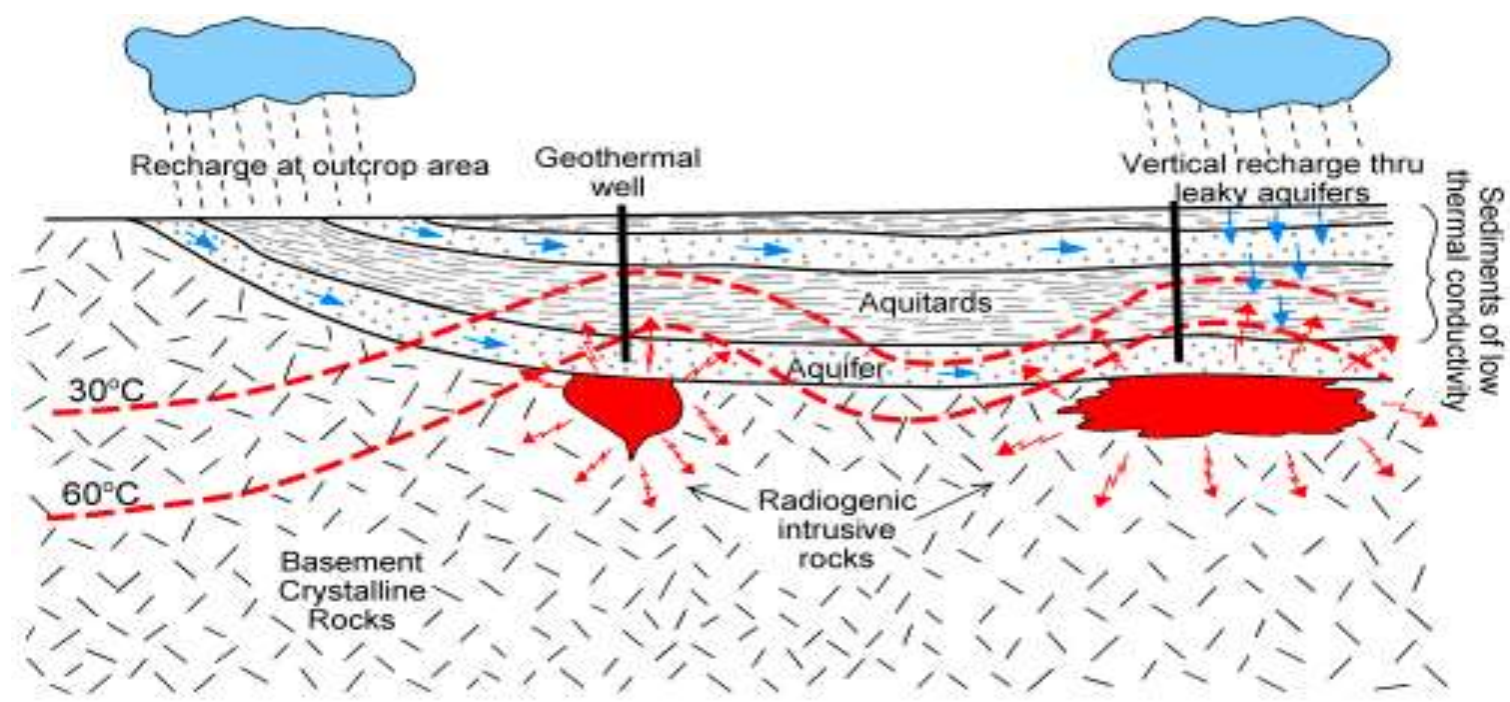

Radiogenic geothermal system (Anderson \& Lund, 1979).

Figure 7. Radiogenic Resources

\subsection{Molten Rock or Magma Resources}

In magma geothermal resources heat is extracted directly from cooling magma on active volcanoes in the crust with high heat. Surface manifestations for such resources are hot springs and fumaroles making the easy to site. However, it is likely that many magmatic geothermal systems have no surface manifestations making them hard to discover, and remain to be discovered (Williams, et al., 2001). Drilling into magma a huge engineering challenge but its success may mark a new age of geothermal power generation. Whereas existing geothermal projects around the world use water or steam heated to less than $300^{\circ} \mathrm{C}$, magma can yield very high temperatures beyond critical temperature for steam. water at the most extreme temperatures exists in a state described as "supercritical", where it behaves as neither a true liquid, nor a true gas, and is capable of retaining a phenomenal amount of energy. Supercritical water with temperature up to $1,000^{\circ} \mathrm{C}$ and saturated with corrosive chemicals has higher capacity and can generate up to ten times more power than conventional geothermal sources (Rowley, 2016).

The discovery of magma as a geothermal resource was more of an accident. According to Schwartz (2011), it happened in 2009 when a team of researchers drilling a 15,000-foot-deep geothermal well in Iceland's Krafla volcano stumbled upon magma, which was flowing into the well at a depth of 6,900 feet-only the second time magma has slipped into a geothermal well during drilling

Molten rock or magma resources contain significant heat energy which can be extracted. This has been experimentally done in Hawaii by drilling into molten rock to directly extract heat energy through a heat exchanger. It has also been used successfully in 
Iceland at Heimaey after the 1973 volcanic eruption. In this case, a heat exchanger was constructed on the surface of the lava flow to recover heat from boiling water that percolated from the surface. In this project, the heat was used for space heating for over 10 years but was then shut down as the lava cooled down (Lund, 2009). Therefore, this geothermal resource is not yet sustainable since the resource is not permanent and more research and development is needed to improve the conversion efficiency and sustained heat recovery from lava or magma. Karytsas and Mendrinos (2013) estimate that magmatic resources have about 327, 360 billion TOE which is about 400 times the total fossil fuel reserves.

Figure 8: Molten Rock or Magma Resource geothermal plant

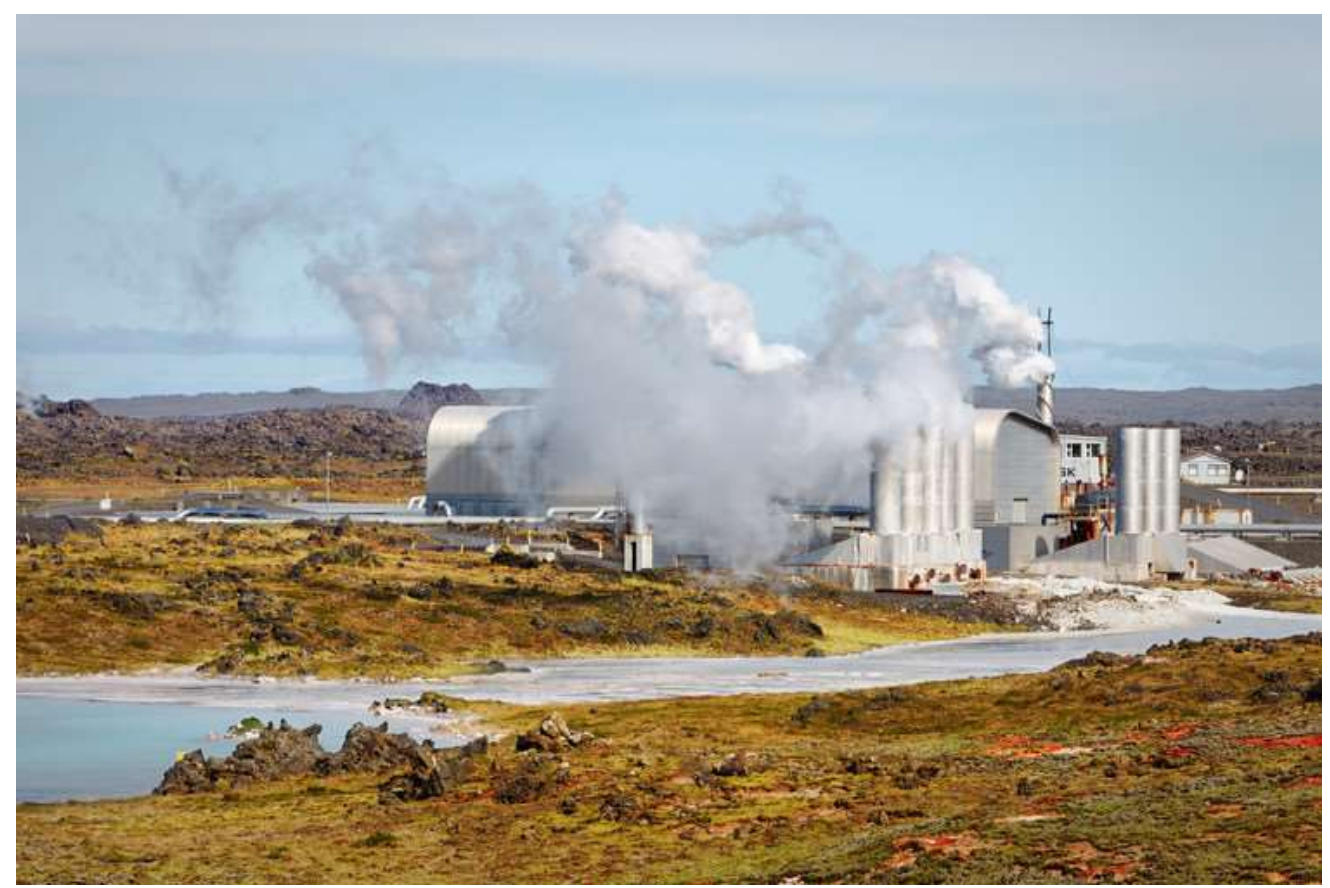

A plant using magmatic resource adopted from (Roley, 2016).

Figure 8. A plant in Iceland using magmatic power.

In Iceland, The Iceland Deep Drilling Project (IDDP) drilled to depths below 4km in the Icelandic crust. In 2009, during their first drilling leg, they accidentally hit a magma pocket, and eventually stabilized the system to create the hottest steam ever produced in geothermal exploration which was $450^{\circ} \mathrm{C}$. As a development, second borehole to follow had an objective of tapping the deep circulating water which penetrates the rock around a magma chamber below the Reykjanes peninsula near Reykjavik (Rowley, 2016). These demonstrates the potential of magma resources for electricity generation.

\subsubsection{Supercritical Geothermal Resource}

Supercritical resource are very high temperature systems located close to the brittle-ductile transition zone in the earth's crust. If the resource exists as water, the temperature of such a resource would be above 374 and pressure of 221 bars. Supercritical fluids or resources are found at the foot of volcanic heated hydrothermal system. These systems have been encountered at Menengai in Kenya, Krapla in Iceland, Los Humeros in Mexico, The Geysers at Salt Sea, Kakkonda in Japan and Larderello in Italy. (Reinsch, 2017). According to Younger (2015) supercritical root zones do occur just above young magmatic intrusions than often exist under a high enthalpy reservoir. He remarked that there are several engineering limitations to accessing and harvesting resources with temperature above $400^{\circ} \mathrm{C}$ and high pressure above $22 \mathrm{Mpa}$.

In several cases, magma has been encountered in supercritical resources for example wells MW-04 and MW-06 in Kenya's Menengai geothermal field where temperature of 390 was encountered pressure of 140 bar during shut down. Such conditions lead to challenges like delay in am drilling. Drilling under such conditions leads to metal fatigue and trouble with cement setting some wells in supercritical resources are dry indicating very low permeability. The wells also experience issues regarding rockphysical and fluid properties, leading to challenges related to well drilling, well completion, and fluid handling and control. Cases of well violently blowing out have been encountered hence formation cave-in, blockage of the drill string, and debris accumulation in the well (Reinsch et al, 2017).

To manage supercritical resources exploration and imaging technologies prior to drilling, and better reservoir modeling is necessary. To improve reservoir understanding at supercritical conditions, laboratory experiments at these conditions and numerical models capable of handling supercritical fluid conditions necessary. Tsuchiyaa, and Yamadab (2017) noted that 
whereas supercritical resources contain significant quantities of recoverable energy, drilling technology to this resource is the limiting factor. Figure 9 gives an illustration of supercritical geothermal resource.

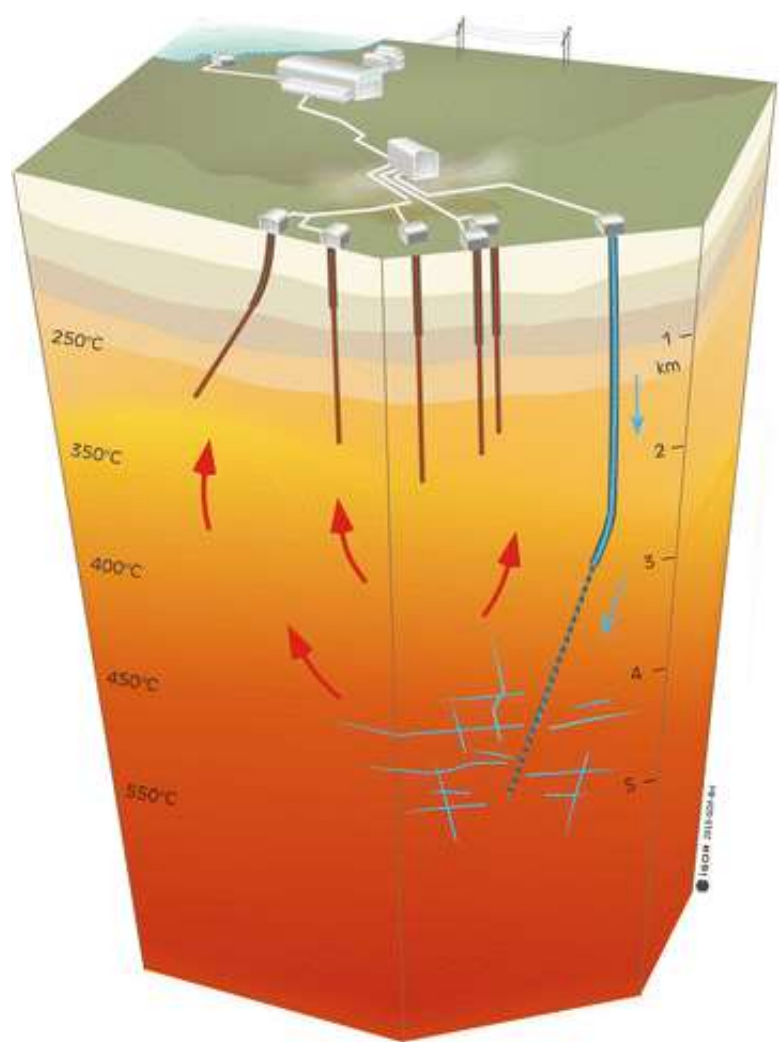

Super critical geothermal resource (Adopted from Yamadab, 2017).

Figure 9 shows main elements of a supercritical geothermal resource which include very high temperature source and very high pressure of geothermal fluid.

\section{Figure 9: Supercritical Geothermal Resource}

\subsubsection{Low-Temperature and Co-Produced Resources}

Low-temperature and co-produced geothermal resources are typically found at temperatures of 300F (150C) or less. Some low-temperature resources can be harnessed to generate electricity using binary cycle technology. Co-produced hot water is a byproduct of oil and gas wells in the United States. This hot water is being examined for its potential to produce electricity, helping to lower greenhouse gas emissions and extend the life of oil and gas fields (National Renewable Energy Laboratory, n.d.). According to Matek (2016) the technology involves use of fluids resulting from oil and gas field development for production of geothermal power/energy.

\subsection{Geothermal Manifestations}

The commonly observed manifestations of geothermal energy are related to convective heat flow and they include hot springs, geysers, fumaroles, volcanic activities like movements of magma to land and sea floors and existence of some economically Significant ant minerals deposits that are geothermally heated by geothermal fluids and deposited and regions of low temperature on or near the surface of the earth (Goldstein, et al. 2010).

\subsection{GEOTHERMAL ELECTRICITY GENERATION AND HEAT APPLICATIONS}

Deep geothermal resources with temperatures above $90^{\circ} \mathrm{C}$ have proved to viable resources for electricity generation often requiring deep drilling between $1500 \mathrm{~m}$ and $4500 \mathrm{~m}$ or as deep as 2 miles underground (Alberta Geothermal Development Council, 2019; US Energy Information Administration, 2017). According to the US Energy Information Administration (2017) for geothermal electricity generation, geothermal hydrothermal resources in form of water, steam or both with high-temperature of $300^{\circ} \mathrm{F}$ to $700^{\circ} \mathrm{F}$. The geo-fluid from deep underground then powers a turbine that generates electricity.

Geothermal operators or power plants generate electricity by either using the steam extracted from geothermal fields directly in a turbine or by using hot pressurized geothermal fluid to vaporize a low temperature boiling point fluid (normally an organic 
fluid) for use in a binary turbine cycle. Steam turbines are typically used in high temperature resources while binary plants are used in intermediate temperature geothermal systems. In both these generation systems, pressurized vapor passes through a turbine and is subsequently condensed in a condenser. The passage of vapor as it expands through turbine stages spins the turbine which turns a generator directly coupled to the turbine shaft to produce electricity (Word Energy Council, 2016).

\subsection{Geothermal Power Generation Technologies and Power plants}

\subsubsection{General Construction of geothermal power plants}

To exploit a geothermal resource for power generation from a hydrothermal system, one or more production wells are drilled to extract and direct steam from the subsurface to the surface where it is guided to a turbine in a power plant for electricity generation. The geothermal fluid which is then condensed form is injected back to the original formation where it came from via the reinjection wells. Almost all power plants today are in hydrothermal systems. Production wells may deliver dry steam, hot water or a mixture of steam and water (Karytsas \& Mendrinos, 2013).

Geothermal power plants use steam produced from reservoirs of hot water or steam several meters or kilometers below the Earth's surface. There are four types of geothermal power plants: dry steam, flash steam, and binary cycle which form the three basic types and combination type which combines more than one of the three basic technologies. Figure 10 below illustrates the general configuration of a geothermal power plant with main elements of a geothermal power plant which includes production wells, reinjection well, the turbine, generator, separators, condenser, cooling towers, main steam lines and other equipment performing different roles in the power plant.

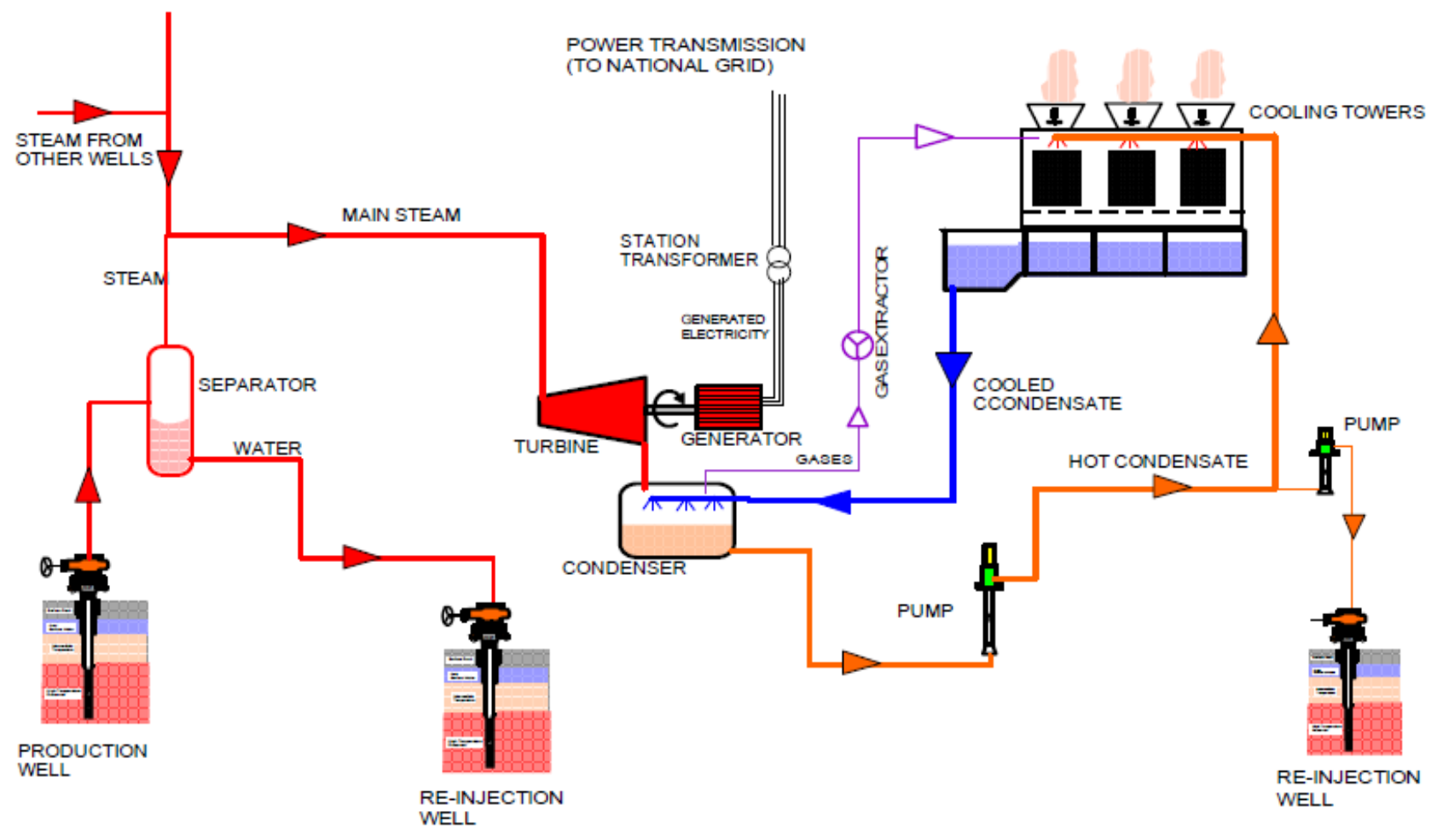

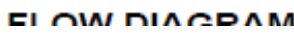

Adopted from (Karytsas \& Mendrinos, 2013).

\section{Figure 10: Constructional/design features}

\subsection{Types of Geothermal Power Generation plants and Technologies}

According to Renewable Energy World (n.d), there are different technologies involved in geothermal generation based on the nature of steam and desired plant efficiency. They include;

i.) Dry steam power plants: These power plants use hydrothermal fluids that consist of dry steam. In these power plants steam is drawn from the underground and directed into a turbine/generator unit that turns a generator, hence generating electricity. This technology was first used in 1904 at Lardarello in Italy which is also the oldest type of geothermal power plant. There are only two known underground resources of steam in the United States namely. The Geysers in Northern California which is the world's single largest source of geothermal electricity and Yellowstone National Park in Wyoming, which has a geyser called Old Faithful. The beauty with these power plants 
is that they emit only steam and minor amounts of gases hence are less polluting to the environment (Geothermal Association, 2014; Renewable Energy World, 2016). Figure 11 bellow illustrates a dry steam power plant.

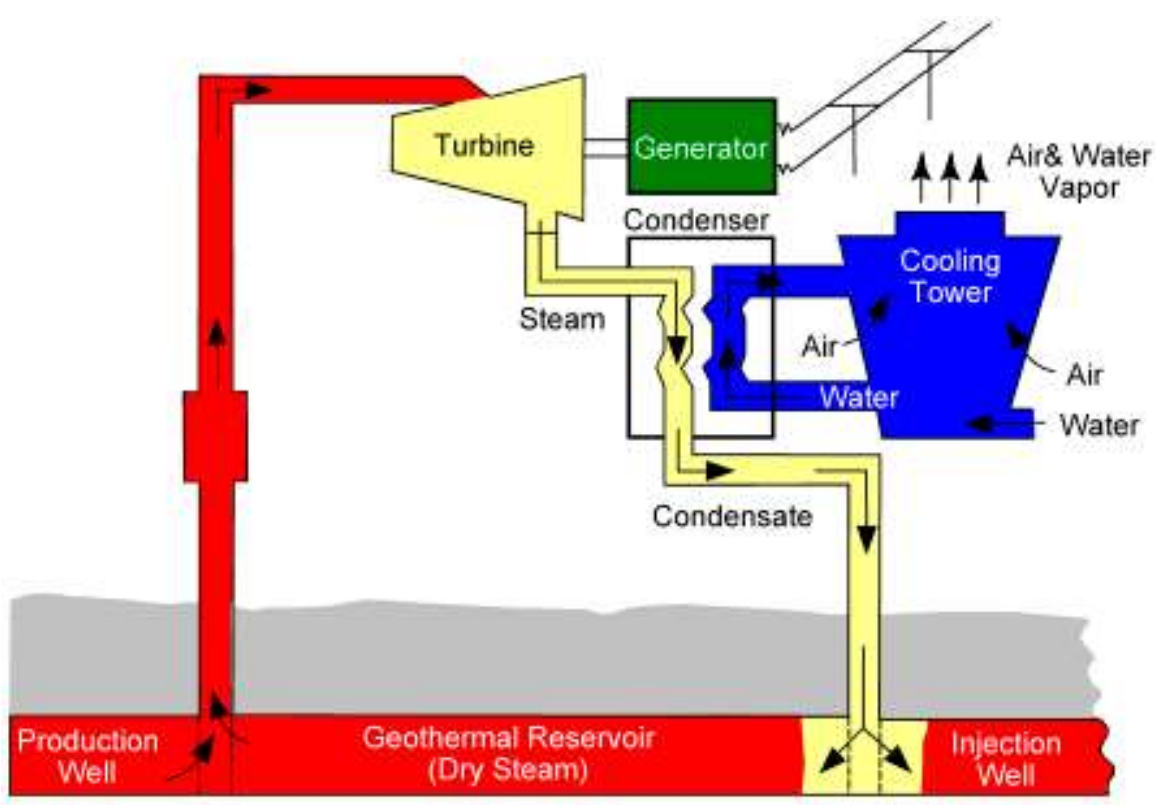

Dry steam powerplant ( Lund, 2009).

Figure 11: Dry steam power plants

Karytsas and Mendrinos (2013) observed that steam from production well is delivered directly to the steam turbine with condensed exhausted reinjected through reinjection wells. They give other examples of dry steam plants as Kamojas in Indonesia. Generally, these plants are rare globally. Olkaria geothermal power plants in in Kenya are dry steam power plants except for Orpower Power plant which is in the same steam field but used binary technology. The average power plant size is 45 MWe.

ii.) Flash/Double flash steam power plants: These power plants use water with temperatures greater than $360^{\circ} \mathrm{F}\left(182^{\circ} \mathrm{C}\right)$. The hot water flows up through wells in the ground under its own pressure and is directed to a flash chamber where pressure is held much lower than the fluid pressure forcing some of the hot water to boil/flash into dry steam. The steam is then separated from the water and used to power a turbine/generator. In double flash, any liquid that remains in the tank of flash chamber is flashed again in a second flash chamber maintained at much lower pressure than the first flash chamber to generate extra steam and hence energy (Geothermal Association, 2014; Renewable Energy World, 2016). Figure 12 bellow illustrates a flash steam power plant. 


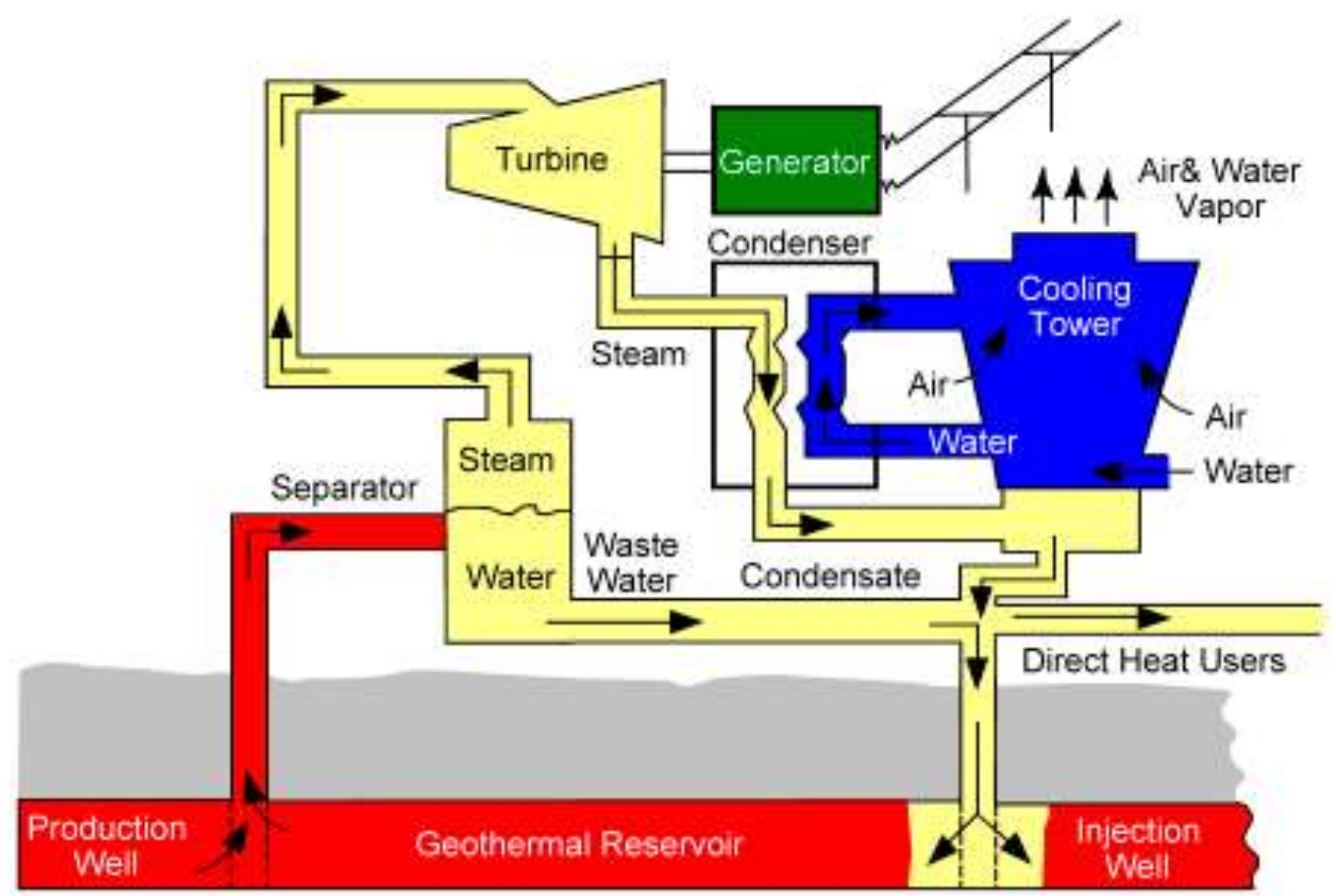

Flash steam plant (Lund 2009).

Figure 12: Flash/Double flash steam power plants

According to Karytsas and Mendrinos (2013) flash power plants deliver a mixture of steam and water to a flash plant which then separated steam and water due to sudden drop in pressure at constant enthalpy. The steam generated is directed to a steam turbine where it expands to run a turbine and hence generate electricity. The resultant water can be flashed further to more steam at a lower pressure and used to generate more power. The water can also be used in cogeneration plant before reinjection through the reinjection well. A flash plant is economically viable if the resource temperature is above $150^{\circ} \mathrm{C}$. The average power plant size is $30 \mathrm{MWe}$ for flash power plants.

As far as application of flash power plants is concerned Wada, Maedomari, and Furuya (2017) remarked that flash type geothermal steam turbine is needed to operate under corrosive steam condition, unlike using clean steam such as thermal power generation or nuclear power generation. Therefore, flash type geothermal steam turbine need to high level technology

iii.) Binary cycle power plants/Organic Rankine cycle system/kalina: These power plants operate on water at lower temperatures of about $225^{\circ}-360^{\circ} \mathrm{F}\left(107^{\circ}-182^{\circ} \mathrm{C}\right)$. Heat from the hot water is used to boil an organic compound with low boiling temperature, like propane which boils at $28^{\circ} \mathrm{C}$. Others are isobutene and pentafluoro-propane. The heated fluid expands in a turbine and exhausted working fluid is cooled, condensed and pressurized. The working fluid is then vaporized in a heat exchanger and then used to turn a turbine coupled to a generator for electricity generation. The water and the working fluid are kept separated by a heat exchanger during the whole process, so there are little or no air emissions. Geothermal water is then reinjected in a closed loop, separating it from ground water sources hence further lowering emissions. Therefore, the binary plants use an organic Rankine cycle system. Binary geothermal power plants have made it possible to produce electricity from resources lower than $150{ }^{\circ} \mathrm{C}\left(302^{\circ} \mathrm{F}\right)$ and about $20 \%$ of geothermal power plants use this technology (Geothermal Energy Association, 2014; Goldstein, et al, 2010; Renewable Energy World, 2016). Therefore, binary cycle plants use two fluid on closed loops. Figure 9 bellow illustrates a binary cycle or organic Rankine cycle geothermal power plant.

According to Karytsas \& Mendrinos (2013) where the geothermal resource generally between $100-180^{\circ} \mathrm{C}$ production and delivery of hot water is done with the aid of a submersible or line shaft pump to feed water to the power plant in a closed loop for heating a secondary fluid which is heated through a heat exchanger and upon vaporization and superheating is used to drive a turbine for power generation. The average power plant size is 5MWe. Figure 13 bellow illustrates an organic Rankine geothermal PowerPoint. 


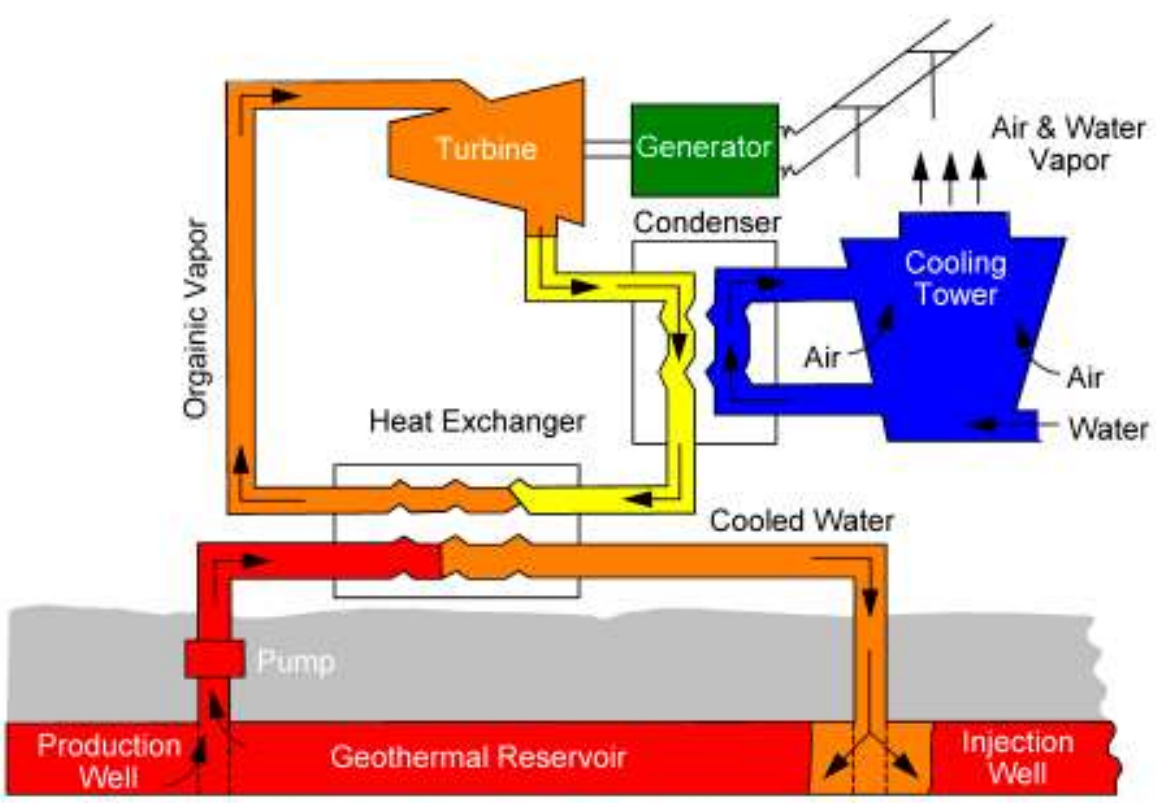

Organic Rankine Cycle or Binary Powerplant (Lund, 2009).

Figure 13: Binary cycle power plants/Organic Rankine cycle system/kalian

Figure 13 above shows major elements of a binary plant as primary fluid which is geothyermal fluid, low temperature boiling secondary fluid, cooling tower, turbine and generator units, production and reinjection wells, a heat exchanger amoung others.

The economy of a binary power plant depends on the characteristics of the geothermal area, i.e. depth to the water level and pumping requirements. Binary technology is feasible for the production of electricity from geothermal may be viable for temperature from $90^{\circ} \mathrm{C}$ if the circumstances are favorable. Larger plants are more economical than smaller units. Binary power plants are best suited as base load plants connected to a large grid, but can also be operated for a small grid in combination with a diesel power plant and may not feasible as the only plant connected to a small grid in island operation (Verkis Consulting Engineers, 2014). Therefore for a successful geothermal binary power plant project it is important to verify all the main characteristics of the geothermal resource prior to the final design of the plant and selection of equipment. The main characteristics are:
i. Extend or size of geothermal field.
ii. Overal capacity of the geothermal resource.
iii. The geothermal fluid temperature
iv. Fluid flowrate from each well v.s drawdown in the well or wellhead pressure.
v. Spacing of wells from one another
vi. Composition of the geothermal fluid and chemiacl properties `.
vii. Effect of fluid reinjection on flow rates from wells and field capacity.

\section{iv.) Hybrid/Combined Cycle/ Combination of basic technologies Power plant}

A combination of any of the above technologies can also be adopted depending on the quality or characteristics of the geothermal resource. This can include flash and binary, dry steam and flash or dry steam, flash and binary combined. In a flash/binary plant, geothermal fluid is flushed steam which is fed to a steam turbine while the separated liquid from the flash chamber is directed to a binary cycle plant for extra power generation (Geothermal Energy association, 2014). A combined plant can therefore be said to be a hybrid plant. Figure 14 below illustrates a hybrid plant. 


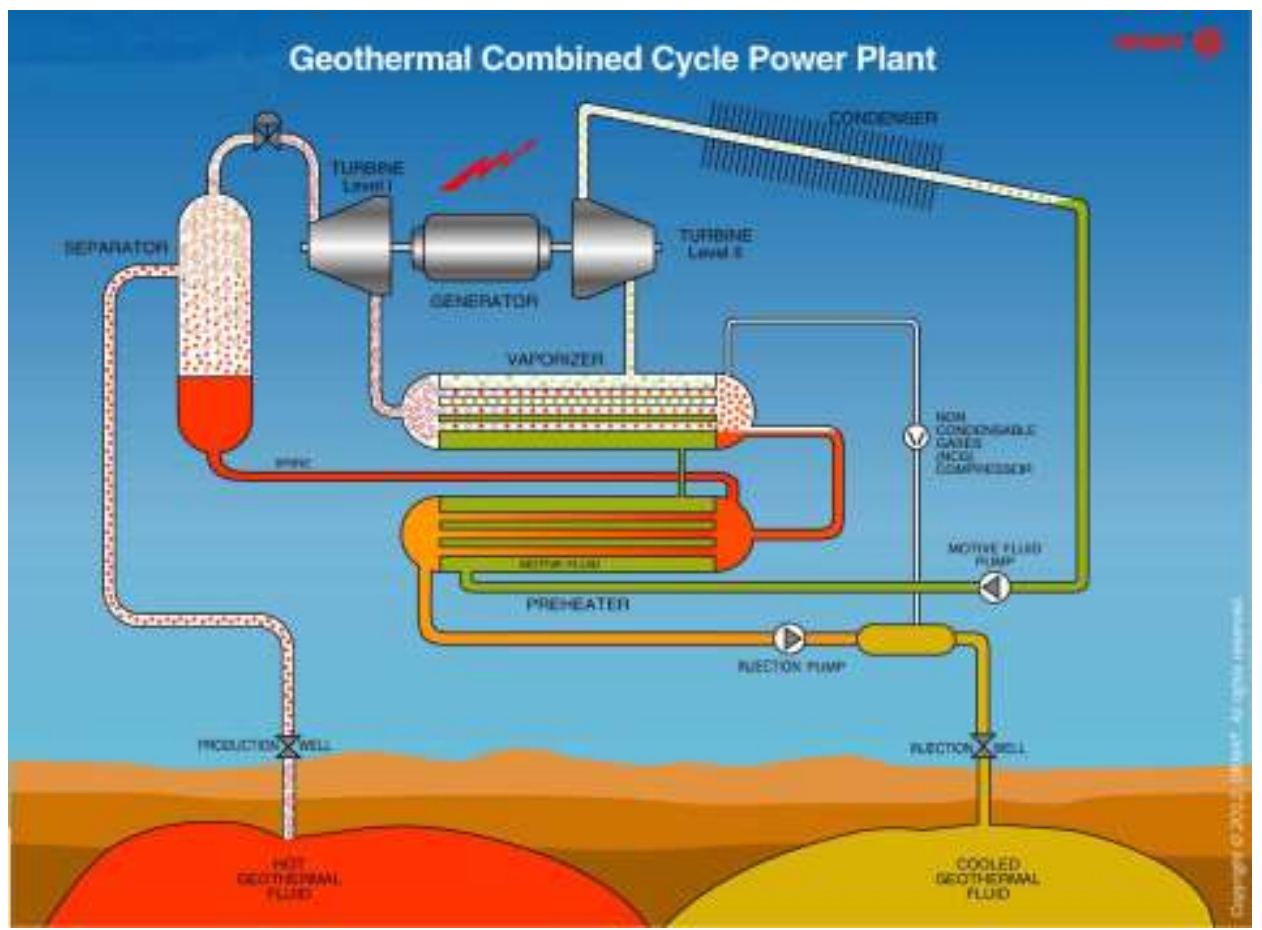

Adopted from Geothermal Energy Association, 2014

Fig 14: Hybrid/Combined Cycle/ Combination of basic technologies Power plant

Figure 14 above illustrates a combined cycle power plant whose main features include a separator, steam turbine and electricity generator, production well, re-injection well, heat exchanger, secondary working fluid, others depending on which basic technologies are being combined for the plant.

According to DiPippo (1999) geothermal fluids exist in a wide range of physical and chemical properties including temperature, pressure, non-condensable, gases, scaling and corrosion potential, the basic power generation systems can be combined in suitable ways to achieve better or more effective systems. Examples of combinations are; direct steam/binary, single flash/binary, hybrid fossil/geothermal systems, etc. A properly designed system should give higher efficiency.

\section{v.) Enhanced/Engineered Geothermal Systems}

The Engineered Geothermal system aims at exploiting hot rock that cannot be accessed using conventional geothermal technology (Bronicki, 2016). EGS provide geothermal power by tapping into the Earth's deep geothermal resources that are otherwise not economical due to lack of water, location, or rock type. The U.S. Geological Survey estimates that potentially 500,000 megawatts of EGS resource is available in the western U.S. or about half of the current installed electric power generating capacity in the United States (National Renewable Energy Laboratory, nd).

The capacity of geothermal reservoir to flow hot fluids can be improved by techniques like hydraulic fracturing, acidification and creation of artificial fluid paths in the enhanced or engineered geothermal systems (Goldstein, e al. 2010). According to Karytsas and Mendrinos (2013), the EGs is drilled from 3-5 km deep and its feasibility was proved by the Soultz project funded by the European Union. Figure 15 bellow illustrates engineered resources. 


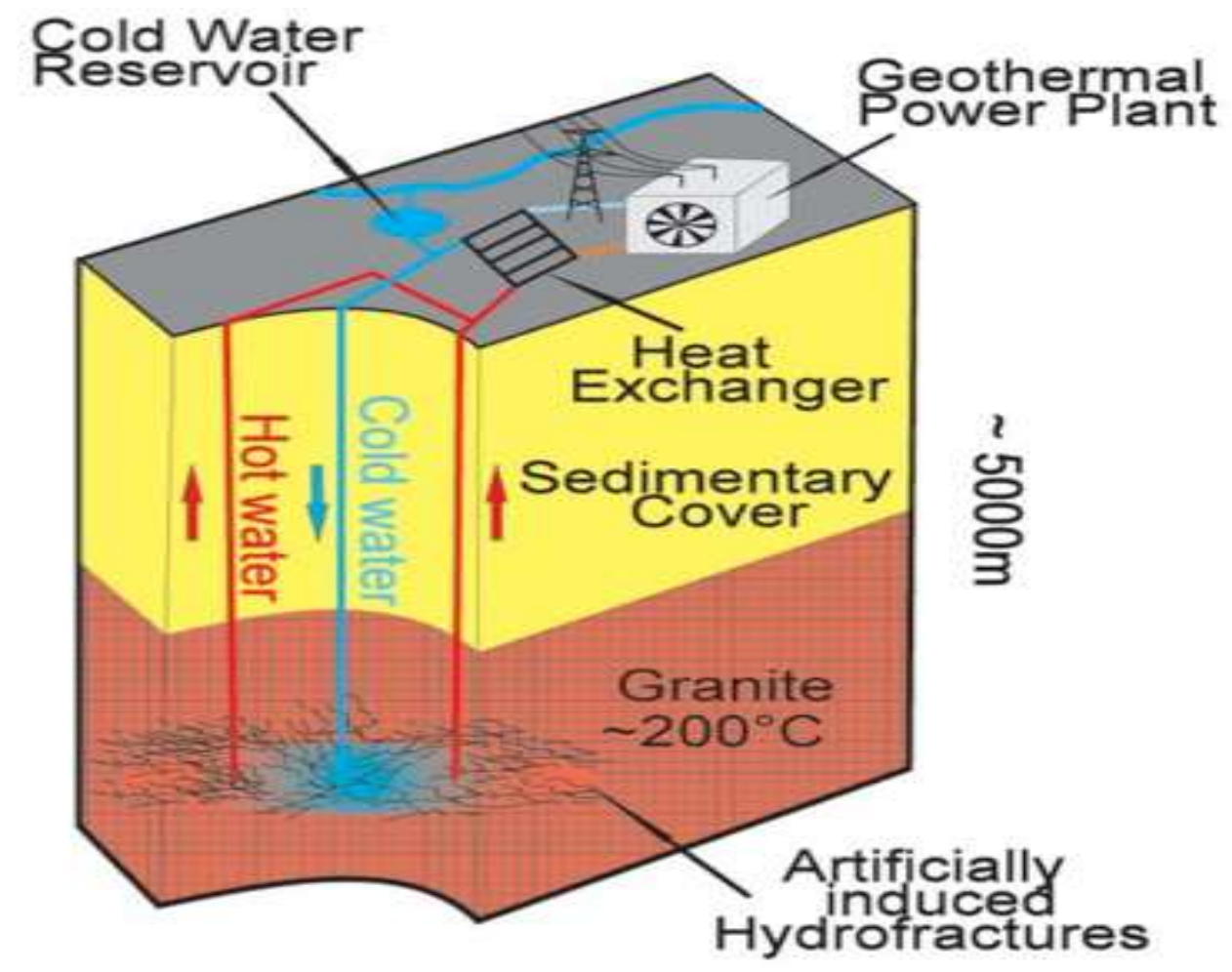

Enhanced/engineered resources (Goldstein, e al. 2010).

Figure 15: Enhanced/Engineered Geothermal Systems

Figure 15 shows a section through a dry rock geothermal system showing granitic and sedimentary rocks and drilled inlet and outlet wells.

\subsubsection{Engineered Power plant}

The first attempt at this hot dry-rock technique was carried out by scientists from the Los Alamos laboratory in New Mexico in 1973. Other experiments have been undertaken out in Japan, France, Germany and UK. A typical example is the project at Soulez-sous-Forets in France where boreholes are drilled to $5 \mathrm{~km}$ under the surface and high temperature reached of say $201{ }^{\circ} \mathrm{C}$ found. And used for generation of 1.5 MWe. Based on pilot schemes such as this, estimates suggest that a commercial hot dryrock system will need to provide 10-100 MW of generating capacity over at least 20 years to be economical. The technology is still in an early stage of development and it is likely to be $10-15$ years before commercial exploitation is possible. Figure 16 illustrates a typical 6ngineered power plant. 


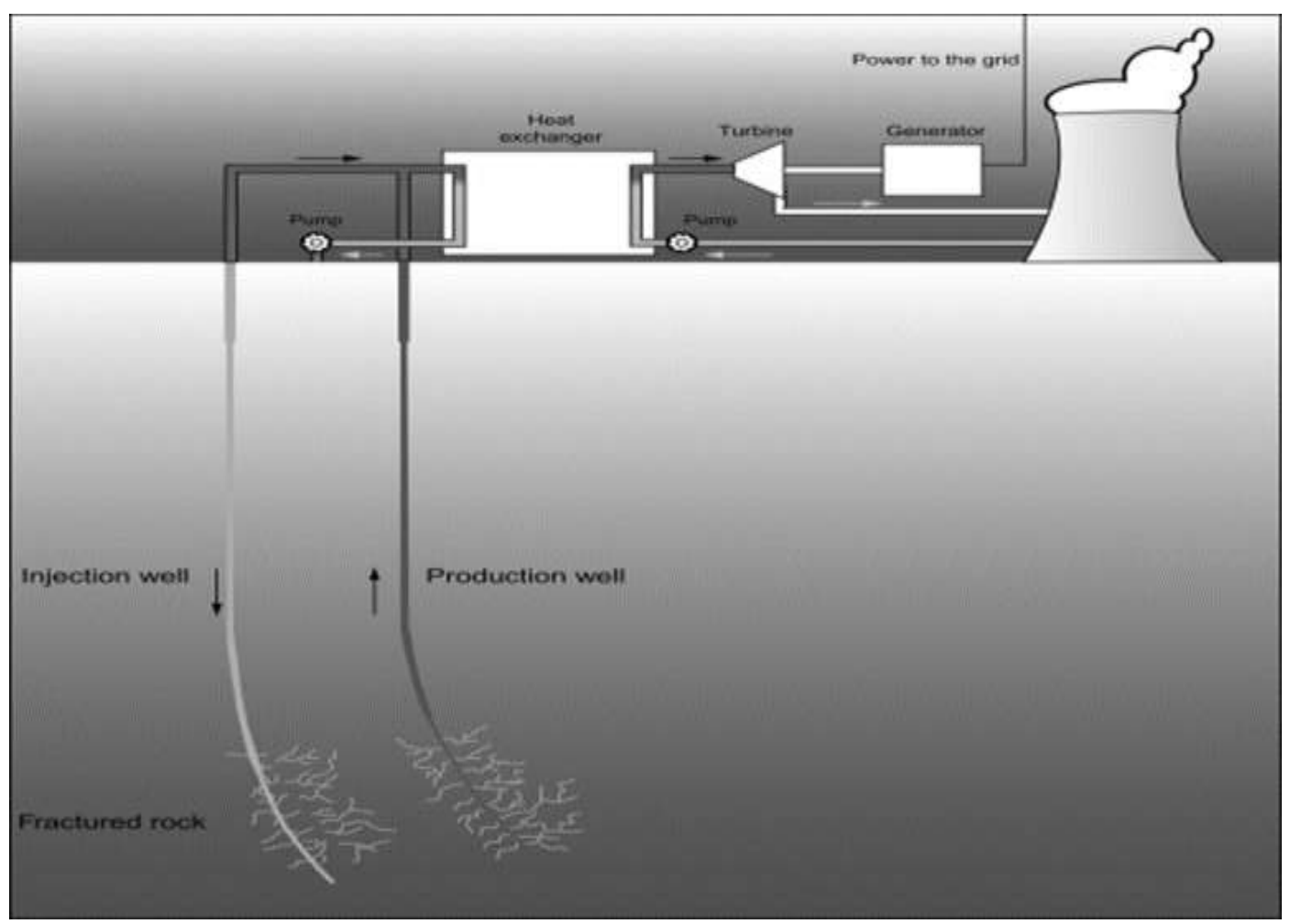

Features/design of engineered power plant (Goldstein, e al. 2010).

Figure 16: Engineered power plant

Figure 16 illustrates an engineered power plant which consists of injection and production well, fractured rock structure, heat exchange, pumps for the fluid, turbine, generator, cooling tower and working fluids, both primary(water) and secondary fluid.

\subsection{Choice of Technology}

According to Matek (2016), the choice of technology depends on the prevailing characteristics of the geothermal resource with binary plants used in low temperature resources while flash and dry steam technologies are used for high temperature geothermal resources. Flash technologies which include single flash, double flash and triple flash constitute 58\% of global electricity capacity, dry steam constitute $25 \%$ while binary constitute about $16 \%$ nontraditional types including back pressure constitute about $1 \%$. Therefore, flash plants are the most prevalent geothermal Power plants. Regionally, in the US and Europe binary projects are plants under development while in East Africa and South Pacific countries several flash and dry steam plants are under development. According to Karytsas and Mendrinos (2013), hydrothermal systems with wells drilled to 2-3 km deep is currently a mature technology, enhanced geothermal systems (EGs) at 3-5 km depth is a new technology under development while supercritical systems at $5-10 \mathrm{~km}$ provide potential for future technology development and exploitation. To maximize electricity output, binary plants can be combined with flash power plants.

\subsection{Benefits of Geothermal Electric Power}

Geothermal power has several benefits compared to many other sources of power. According to Huttress \& Moletto (n.d.), Khemani, H. (n.d.), the benefits include the following;

i.) Provides clean and safe and renewable energy using little land

ii.) Generates continuous, reliable power at high load factor and capacity factor making it ideal for base load power generation.

iii.) No combustion of fuels hence conserves fossil fuels and contributes to diversity in energy sources hence reduced demand for fossil fuels and hence reduced pollution and power plant equipment needs.

iv.) Avoids importing and benefits local economies in terms of foreign exchange savings and security of power supply in case of conflicts.

v.) Offers modular, incremental development and village power to remote site where almost all the geothermal sites are located hence leads to improved quality of life amongst surrounding or neighboring communities. At community level, more so in rural settlements, Kollikho, \& Rivard (2013) observed that provision of cheaper and environmentally friendly power, economic growth and creation of employment opportunities are some of the key benefits of geothermal energy utilization 
vi.) Geothermal plants have low fresh water requirements and use about 20 liters of freshwater per MWh, while binary air-cooled plants use no fresh water, as compared to a coal plant that uses 1,370 liters per MWh. An oil plant uses about $15 \%$ less and nuclear about $25 \%$ more than the coal plant. The only change in the fluid during use is to cool it, and usually the fluid is returned to the same aquifer, so it does not mix with the shallow groundwater. At the Geysers facility in Northern California, 42 million liters of treated wastewater from Santa Rosa are pumped daily for injection into the geothermal reservoir, reducing surface water pollution in the community and increasing the production of the geothermal field. A similar project supplies waste water from the Clear Lake area on the northeast side of the Geysers. These projects have increased the capacity of the field by over $100 \mathrm{MWe}$.

ix.) Geothermal power plants are designed camouflage with the surrounding landscape and can be located near recreational areas with minimum land and visual impacts compared with coal power plants

x.) They generally consist of small modular plants under $100 \mathrm{MWe}$ as compared to coal or nuclear plants of around 1,000 MWe and hydropower plants which re generally bigger Typically, a geothermal facility uses 404 square meters of land per GWh compared to a coal facility that uses 3,632 square meters per GWh and a wind farm that uses 1,335 square meters per GWh.

xi.) Less land area is required to set up a geothermal plant per megawatt of power produced is much lesser than that required for the other types of power plants like coal power plants.

xii.) Geothermal power is not affected by seasonal variability of weather conditions unlike other plants like hydropower plants, wind and solar. The energy from geothermal reservoir is available 24 hours a day and all the days of the year without any breakage or change during varying seasons, natural disaster and political turmoil.

Therefore, the use of geothermal energy is reliable and can provide base load power; is renewable; has minimum air emission and offsets the high air emissions of fossil fuel fired plants; has minimum negative environmental impacts, is combustion free, and is a domestic fuel source.

\subsection{Disadvantages of Geothermal Power plants}

i.) Emissions are usually associated with steam power plant cooling towers that produce water vapor emission (steam), not smoke. The potential gases that can be released, depending upon the reservoir type are carbon dioxide, sulfur dioxide, nitrous oxides, hydrogen sulfide along with particulate matter. A coal- fired power plant produces the following kilograms of emissions per MWh as compared to a geothermal power plant: 994ppm vs. up to 40 for carbon dioxide, 4.71 vs. up to 0.16 for sulfur dioxide, 1.95 vs. 0 for nitrogen oxides, 0 vs. 0.08 for hydrogen sulfide $\left(\mathrm{H}_{2} \mathrm{~S}\right)$, and 1.01 vs. 0 for particulate matter. Hydrogen sulfide is routinely treated at geothermal power plants and converted to elemental sulfur. In comparison, oil-fired power plants produce $814 \mathrm{~kg}$ and natural gas fired plants 550 $\mathrm{kg}$ of $\mathrm{H}_{2} \mathrm{~S}$ per MWh. Binary power plants and direct-use projects normally do not produce any pollutants, as the water is injected back into the ground after use without exposing it to the atmosphere.

ii.) Noise is produced at a power plant or direct-use site is during the well drilling operation, which normally shuts down at night. The noise from a power plant is not considered an issue of concern, as it is extremely low, unless you are next to or inside the plant. Most of the noise comes from cooling fans and the rotating turbines.

iii.) Subsidence and induced seismicity must be considered when extracting fluids from the ground. These are usually mitigated by injecting the spent fluid back into the same reservoir. There have been problems with subsidence at the Wairakei geothermal field in New Zealand; however, this has been checked by fluid reinjection. Neither of these potential problems are associated with direct-use projects, as the fluid use is small and well, and pipelines are usually hidden. In addition, utilizing geothermal resources eliminates the mining, processing and transporting required for electricity generation from fossil fuel and nuclear resources.

iv.) Negative impact on natural phenomena, wildlife and vegetation Plants are usually prevented from being located near geysers, fumaroles and hot springs, as the extraction of fluids to run the turbines, might impact these thermal manifestations. Most plants are in areas with no natural surface discharges. If plants are located near these natural phenomena, the fluid extraction depth is planned from a different reservoir to prevent any impact. Designers and operators are especially sensitive about preserving manifestations considered sacred to indigenous people. Any site considered for a geothermal power plant, must be reviewed and considered for the impact on wildlife and vegetation, and if significant, provide a mitigation plan.

v.) Geothermal development requires huge investment in exploration and drilling with no guarantee for commensurate power/energy output from the investment as several wells may not yields steam or generally uneconomical to operate. This makes the undertaking financially risky.

vi.) Most geothermal power sites are located far from load centers hence requires long transmission and distribution line hence higher electricity losses. 
vii.) Only few sites have potential of geothermal energy exploitation and location is a challenge often requiring huge capital investments.

viii.) Geothermal resources are often located in areas with active volcanoes hence the location has inherent risks due to volcanic activities.

ix.) Geothermal fluid is generally at lower pressure and temperature resulting to lower plant efficiency of less than $15 \%$ compared to $35 \%-38 \%$ for fossil fuels fuel plants. This is relatively wasteful.

x.) Geothermal power plants require transport of steam over long distance through pipelines from production wells scattered over a wide area leading to enthalpy losses from steam.

xi.) Geothermal plants have high steam requirements for example $100 \mathrm{MWe}$ power plant may require as much as 80 tons/hr leading to high capital requirements due to high specific steam consumptions.

xii.) Geothermal fluids have minerals which cause erosion and corrosion of steam turbine parts like the turbine blade and general performance.

xiii.) Geothermal power plants have significant quantities of non-condensable gases for example in the Geysers at California, $70-80 \%$ of the gases leave in the cooling tower with $20-25 \%$ re-injected back. This gases have the effect of lowering efficiency of heat transfer in heat exchangers.

\subsection{Geo-Exchange and Geothermal Heat Pumps for Shallow Geothermal Applications}

In geo-exchange, a constant temperature is used to provide efficient heating or cooling depending on weather conditions for houses, commercial building or even industrial establishments. A heat pump is used to concentrate the heat from the earth then transfer to cold space through ducting's or during winter while during summer, heat is extracted from the space air and transferred to the ground. Technical, in geo-exchange the earth is used as a battery (Geothermal Energy Association, 2014; North Alberta Development Council, 2019).

Heat pumps are a form of heat engine using mechanical work to transfer heat from a low temperature source to a higher temperature sink. There are various applications of heat pumps but in but for the case of geothermal applications, the concern is to transfer heat between buildings and the external environment by either rejecting heat to the environment and cooling the building or extracting heat and heating the building. Different forms of thermodynamic cycle can be used to move heat between source and sink. The principle components or elements in a heat pump are a refrigerant, pump or compressor, high temperature source and high temperature sink with the earth acting as high temperature source in winter but in summer it acts as low temperature sink. The enthalpy changes in the condenser and evaporator indicate the heat transfer rate per unit mass of refrigerant flowing (Rees, 2016). Therefore heat pumps work as reverse of refrigerating cycles. The advantage of heat pumps is that the work done to provide heating and cooling is less than work done to move heat from source to the sink hence the process is efficient (Rees, 2016).

Geothermal Heat Pumps are functional during both winter and summer with the principle of constant temperature in the earth is applied to geothermal heat pumps. Generally, geothermal heat pumps use the average ground temperatures of $40^{\circ}$ and $70^{\circ} \mathrm{F}$. The first geothermal heat pump was developed at The Ohio State University for residential use in 1946 that was followed by a groundwater heat pump at Oregon at about the same period (Geothermal Association, 2014).

Geothermal heat pumps have realized significant growth in applications. According to Lund et.al (2004) GHPs have contributed to high growth rates of geothermal applications between 2003 and 2004 with over $10 \%$ growth rates in more than 30 countries around the world.

\subsection{Direct Geothermal Heat Applications}

Direct heat applications are used where the geothermal resource is bellow $90^{\circ} \mathrm{C}$ and inform of water or generally $90^{\circ} \mathrm{F}$ and $200^{\circ} \mathrm{F}$ (Geothermal Energy Association, 2014; North Alberta Development Council, 2019). Other applications space heating and cooling, food preparation, hot bathing and spas, agriculture, aquaculture like fish farming, greenhouses, snow melting, thermal industrial processes, traditional healing purposes (Popovski, 2003; Younger, 2015). Other typical examples include, healing application e.g. President Franklin D. Roosevelt of the United States, frequented Georgia's hot springs and founded the Roosevelt Warm Springs Institute for polio treatment in 1927. Another historical case is that of the City of Klamath Falls, Oregon which began using hot springs hot spring water homes heating use as early as 1900 (Geothermal Energy Association, 2014)

\subsection{GEOTHERMAL ELECTRICITY PROJECT DEVELOPMENT CYCLE}

\subsection{Phases in Geothermal Project Development}

According to Monterrosa,(2009) based on his work in Central America, a geothermal project with a 30 MW condensing type power plant could require 7 to 12 years of development with capital investment of $65-80 \mathrm{M} \$$ with most of the time taken in permit and licenses from environmental and regulatory authorities, securing financing and upfront activities. He further noted that risk management is a very important aspect of geothermal project development and that whereas at the beginning the risk is $100 \%$, 
effort should be made to bring the risk to $20 \%$. With risk level of 20, one in every 5 wells drilled will fail Therefore high costs, long gestation Period and high risks are the main challenges affecting geothermal power projects.

The entire geothermal project can be divided into exploration (prefeasibility), drilling (feasibility) and development (production wells, reinjection wells, steam gathering system and power plant construction and commissioning) followed by operation and maintenance of the plant (Monterrosa, 2009). This shows that a geothermal project cycle has got so many phases or stages to be followed making the project time consuming and expensive to develop.

According to Chiasson (2016) project development is a process that takes a project conception to construction, implementation and/or commissioning. The major phases in geothermal project development are;

\subsubsection{Reconnaissance Phase}

This phase is done by a geoscience consultant firm and takes up to one year and accounts for up to $3 \%$ of total project cost. In this phase, thousands of kilometers techniques used include geological mapping, geochemical sampling aerial photography and remote sensing.

\subsubsection{Prefeasibility Phase}

This is a more concentrated study of the target area covering hundreds of square kilometers and done typically by a geoscience consulting company and may take up to two years accounting for up to $3 \%$ of total project cost. The objective of this phase is to develop a geological model for use as basis for siting geothermal exploration boreholes. Exploration studies are carried out to define the subsurface structure and additional geochemical studies. Geophysical studies carried out gravity, magnetic, resistivity and seismic studies.

\subsubsection{Detailed Feasibility Study Phase}

This phase aims at confirming the resource and may take up to two years to complete a t a cost of up to $5 \%$ of total project cost. Experts used are mainly geoscientists and reservoir engineers and drilling engineers. The phase involves deep drilling and logging of exploratory wells to reach the geothermal reservoir. The main objective of this phase is to support and refine the geothermal model. Exploration wells are used to quantify resource available. For flow testing of the geothermal resources availability, exploration wells are used as production and injection wells. It is during this phase that significant sourcing of funds is done. The barriers experienced during this phase include site access, environmental and impact assessments and risk of not finding geothermal resources.

The exploration process typically includes the sampling and analysis of waters and gases from hot springs and fumaroles, geophysical measurement of subsurface rock resistivity using the time-domain electromagnetic for $<1 \mathrm{~km}$ depth of investigation while magnetotellurics is done for $>5 \mathrm{~km}$ depth of investigation techniques, and both shallow and deep drilling. The goal of shallow drilling is to identify and map the conductive heat flow anomaly overlying the geothermal system. The main objective of deep drilling during exploration is to penetrate into the geothermal reservoir, if it exists, and produced fluids for analysis (Williams et al, 2001). Figure 17 bellow illustrates deep and shallow wells into a typical hydrothermal geothermal field. 


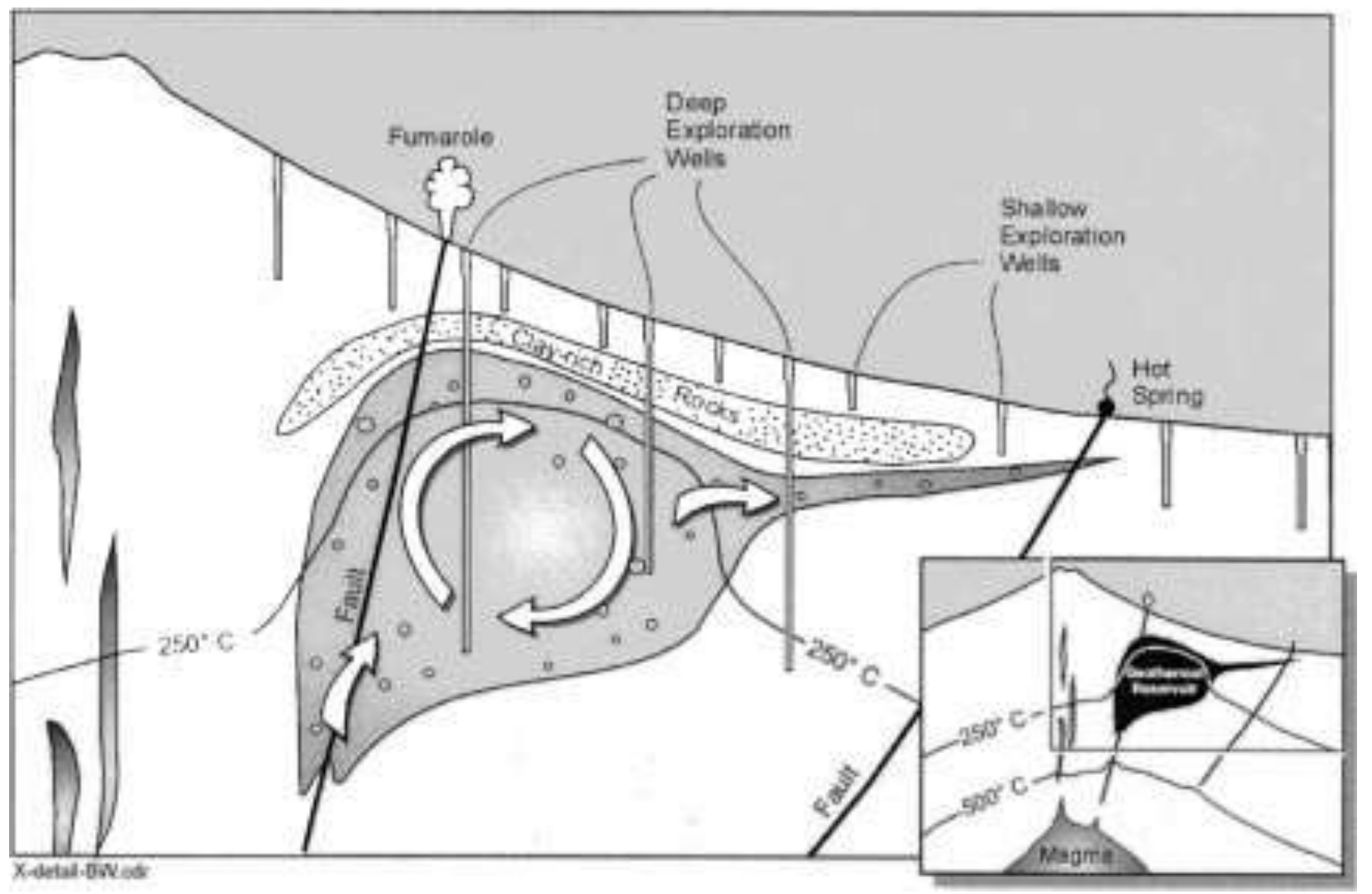

Source Williams et al (2001).

Figure 17: Geothermal deep and shallow exploration wells

Figure 17 shows a schematic cross section through the earth's crust showing the key elements of a typical Volcanic-hosted geothermal system. Main features are magma, fault lines, and surface manifestations like fumaroles, hot springs or geysers

\subsubsection{Engineering and Project Development Phase}

This phase brings the geothermal field to full production level. It takes up to two years to complete and accounts for up to $30 \%$ of the total project cost. Expertise reservoir engineers, drilling engineers. It is during this phase that final legal and regulatory permits. Other studies done in this phase include environment, ecology and social -cultural.

In this phase production and injection wells are drilled, with piping and steam systems designed and constructed then tested and completed. For construction of pipes, pipe materials should correspond to the chemistry of geothermal fluids. The main barriers to the project at this phase are legal and regulatory controls, permits, cultural and community opposition and risk of not finding a feasible resource.

\subsubsection{Procurement, Construction and Commissioning Phase}

This phase is meant to bring the power plant to operation. It takes up to one yearend accounts for up to $60 \%$ of total project cost. Personnel involved include civil engineers, mechanical engineers, and electrical engineers. It is in this phase that the power plant is designed and constructed and transmission lines are also designed and constructed.

\subsection{List of Important Stages in Geothermal Project Development}

According to Kenya Electricity Generating Company Ltd., The planning and development of geothermal development comprises the following stages based on its experience;

a) Review of existing information of a prospect

b) Detailed surface exploration studies

c) Exploration drilling and well testing

d) Appraisal drilling and well testing;

e) The feasibility studies based on gathered data and information.

f) Production drilling, power plant design and environmental impact assessment for the project

g) Geothermal power plant construction and commissioning

h) Reservoir management and further development

i) Shutdown and abandonment 


\subsection{Summary of Phases and Activities in Geothermal Project Development}

According to Bw'Obuya (2002), the Management of Phases of Geothermal Resource Development and utilization can be summarized as shown in table 4 bellow.

Table 4: Summary of phases in geothermal project cycle

\begin{tabular}{|c|c|c|c|}
\hline & Phase & Activities & \\
\hline 1 & Exploration & $\begin{array}{l}\text { i.) } \\
\text { ii.) } \\
\text { iii.) }\end{array}$ & $\begin{array}{l}\text { Reconnaissance Surveys } \\
\text { Detailed Investigation } \\
\text { Exploration Drilling }\end{array}$ \\
\hline 2 & Appraisal & $\begin{array}{l}\text { i.) } \\
\text { ii.) } \\
\text { iii.) }\end{array}$ & $\begin{array}{l}\text { Appraisal Drilling } \\
\text { Reservoir Evaluation and Modelling } \\
\text { Feasibility Study }\end{array}$ \\
\hline 3 & Steam Field Development & $\begin{array}{l}\text { i.) } \\
\text { ii.) } \\
\text { iii.) }\end{array}$ & $\begin{array}{l}\text { Production and injection well } \\
\text { Drilling } \\
\text { Well Testing } \\
\text { Preliminary power plant Design }\end{array}$ \\
\hline 4 & Power Plant Construction & $\begin{array}{l}\text { i.) } \\
\text { ii.) } \\
\text { iii.) }\end{array}$ & $\begin{array}{l}\text { Detailed power plant design } \\
\text { Plant construction } \\
\text { Plant testing and Commissioning }\end{array}$ \\
\hline 5 & Resource Utilization & $\begin{array}{l}\text { i.) } \\
\text { ii.) } \\
\text { iii.) }\end{array}$ & $\begin{array}{l}\text { Operation } \\
\text { Plant Maintenance } \\
\text { Reservoir Management }\end{array}$ \\
\hline
\end{tabular}

The development program from project identification to power station commissioning is about 8 years but can be reduced to 5 years if finances are readily available (KenGen, nd). Therefore, financing is the major cause of long project period and the need to drill several wells to supply enough steam to the power plant.

\subsection{CHALLENGES OF GEOTHERMAL POWER DEVELOPMENT}

\subsection{Long Gestation Period}

Geothermal power generation is valued for its high reliability, independence from short term weather fluctuations, and long operating life. Individual plants, such as Wairakei (NZL), the Geysers (USA), Larderello (ITA), Bulalo (PHL) and Oita (JPN) have reliably generated electricity for over 40 to 50 years. Geothermal generation typically has low operating costs (making them easy to dispatch) but suffers from high up-front capital costs and associated resource risks. (WEC, 2016). Likewise of the reasons why geothermal energy is still not used in a large scale for electricity generation worldwide is that it takes a long time from the time the resource is discovered until the time the power plant is operational (Geirdal, 2013). These explains the low pace of geothermal power development even when the resource is abundant for example, in Kenya, the geothermal resources potential is currently estimated at 10,000 MW, of which only $241 \mathrm{MW}$ was connected to the national grid by 2013 (Mulaha, 2013). This raises serious concerns to development planers and researchers as they seek better and faster ways of developing geothermal generating capacity.

\subsection{High Cost of Surface Installations}

The cost of the surface installations, the power conversion and auxiliary systems, is over $60 \%$ of the total cost of a geothermal power plant. There seems to be a myth that power conversion is a mature technology with little room for improvement. Due to this myth and also due to the obvious and enormous risks associated with the subsurface reservoir assessment and development, almost the entire noncommercial and pre-commercial geothermal energy research and development over the past twenty years have been directed towards subsurface issues, namely discovery, characterization, development, and 
exploitation of the underground geothermal resource. (Gurgencil, H., Rudolph, Saha, T, \& Max Lu, M. 2008). These clearly shows the need to do reach on surface issues concerning power generation efficiencies and technologies.

\subsection{Geological Limitations}

It is not just anywhere in the world that you can exploit geothermal energy. According to Varghese (2016) geothermal power plants can only be built on geological hotspots that exists less than $10 \%$ of our planet with drilling posing real challenges to resource development and exploitation since drilling through the rocky earth is not quite easy. Kilikho \& Rivard (2013) observed that dry well and volcanic hazards make geothermal power exploitation a high-risk undertaking. This is because all successful geothermal ventures require three vital elements;
i.) Existence of hot rock,
ii.) Water and proximity to the geothermal resource.
iii.) Financial resources and potential exploration risks are additional issues to be dealt with.

This further emphasizes the need to improve on delivery in terms of time and cost for this scarce resource.

\subsection{Technological barriers}

According to the European Commission (2014), Technological barriers lie mainly in high exploration and high investment costs for electricity production, long-term investment return, and the risk of failure during the exploration and drilling/stimulation phase of a geothermal project, while technologies for offshore and magmatic exploitation are still at the experimental stage. In addition, regulations and administrative procedures represent obstacles that do not encourage the application and diffusion of this renewable energy. Barriers to larger geothermal energy exploitation for electricity production are the high costs of drilling and power plant construction, the long period for developing deep geothermal projects to commercial deployment, and the risk that electricity production will not reach the projected objectives. Success ratios for both exploration and production wells remain low. On the other hand, World Energy Council (2016), laments that roughly half the capital costs of a geothermal energy system derive from supplying hot fluid or steam from the geothermal field. In addition, the steam field tends to consume most of the ongoing capital expenditure to sustain operations. Therefore, from the foregoing literature, technical barriers, financial costs and long gestation periods prevent faster development and commercialization of geothermal electricity. As the steam field which is needed for a conventional plant unlike the wellhead, it consumes about half of the capital cost.

\subsection{High Overall Project Costs}

Geothermal project costs are highly site-sensitive with typical costs for geothermal power plants range from USD 1870 to USD 5050 per kilowatt $(\mathrm{kW})$, noting that binary plants are normally more expensive than direct dry steam and flash plants. The leveled cost of electricity (LCOE) of a geothermal power plant ranges from USD 0.04 to USD 0.14 per kilowatt-hour (kWh), assuming maintenance costs of USD 110 per kW per year and a 25-year economic life (IRENA, 2017b). However according to Sigfusson \& Uihlein (2015), the costs for geothermal technologies are expected drop through 2050, further improving their adoption and facilitating the growth of geothermal energy.

Karytsas and Mendrinos (2013) remarked that investment costs of the geothermal power plants depend on depth, temperatures, chemistry and flowrates of the geothermal resource. Investment costs however vary globally.

\subsection{Project Financing Challenges}

There is general reluctance by investors to finance high risk early development stages instead preferring to finance production drilling and power plant construction. This is because of huge upfront costs involved in drilling wells that may end up with little or no steam (Kilikho \& Rivard, 2013). The overall effect of huge financial requirement and risk make investment in geothermal power generation expensive, slow and hence less competitive. According to Matek (2016) the World Bank through its geothermal funds have tried to reduce risks associated with geothermal projects in developing countries Djibouti, and Nicaragua. Whereas international donor banks increased financing from $6 \%$ in 2012 to $17 \%$ in 2015, the contribution is still a small fraction of needed funds. Therefore, raising funding for geothermal projects remains a challenge. And governments need to contribute more in additional funding

\subsection{Human Resource Challenges}

Geothermal development faces challenges with human resource in that there is a limited pool of experts like energy development like geoscientists, engineers, and geologists, especially for developing countries like Kenya. As a solution, the United Nations University has been involved in training geothermal specialists for geothermal development. The nature of operations and development of geothermal power plants create numerous challenges to human resources like insurance, housing, transport and logistics, health, and recreational facilities. 


\subsection{Market Barriers}

The market barriers to geothermal development lack or weak regulatory framework, high exploration risks, lack of adequate financing, shortage of qualified personnel. In some countries like the US geothermal development is driven by federal and state incentive packages like easy access to the grid, taxi exemptions e.tc. In developing countries, the World Bank mitigates against risks related to geothermal development and through carbon credits, countries get additional funding and incentives (Karytsas \& Mendrinos, 2013).

\subsection{GEOTHERMAL DEVELOPMENT, ENVIRONMENTAL AND SOCIAL IMPACT}

\subsection{Environmental Impact of Geothermal}

\subsubsection{Air Pollution}

Geothermal energy exploitation is associated with some gaseous emissions. According to Berrizbeitia (2014) and Holm, Jennejohn, and Blodgett (2012), the utilization of geothermal energy releases gases trapped within the geothermal fluid from the earth. These gases include carbon dioxide, hydrogen sulphite, methane and ammonia. The levels of greenhouse gases associated with geothermal energy exploitation are however much lower than the greenhouse gases produced by fossil fuel combustion e.g. Coal, natural gas and oil. These makes geothermal a substitute for fossil fuels in as far as global warming mitigation is concerned.

Holm, Jennejohn, and Blodgett (2012) observed that geothermal power plants emit about $5 \%$ of $\mathrm{CO}_{2}, 1 \%$ of $\mathrm{SO}_{2}$ and less than $1 \%$ nitrous oxide emitted by coal fired power plants of equal size while some geothermal power plants emit zero emissions. It is however difficult quantify the actual emissions from geothermal energy development due to existence of these naturally emitted gases, and inconsistent monitoring from power plants.

Natural geothermal emissions have $\mathrm{CO}_{2}$ as the most commonly released gas. Others though in small quantities are ammonia, methane gas, hydrogen, nitrogen, argon, and hydrogen sulphide. The type of emissions is influenced by the natural chemistry of the geothermal fluid which happens to be specific to a given hydrothermal resource, reservoir temperature, pressure, fluid chemistry, and non-condensable gases content. The power generation technology affects the amount of gaseous emissions with binary power plants emitting less gases as they are retained in the geothermal fluid and reinjected back into the geothermal reservoir. The Enhanced Geothermal Systems (EGS) have shown significant potential to offset $\mathrm{Co}_{2}$ and other gaseous emissions (Holm, Jennejohn \& Blodgett, 2012).

\subsubsection{Water Pollution}

Laboratory examination by Argonne National Laboratories showed that geothermal fluids have high concentration of toxic substances/minerals including antimony, mercury, arsenic and Lead (Berrizbeitia, 2014 \& Glassley, 2010). In a study carried out by Robert Axtmann in 1975 as cited by Berrizbeitia (2014), compared to a coal power plant, Wairakei geothermal power plant in New Zealand discharged 6.5 times as much heat, 5.5 as much water and 0.5 as much Sulfur. It was also found out that contamination of the Waikato River occurred with hydrogen sulfide, carbon dioxide, arsenic, and mercury at concentrations that had adverse effects. However, the study was done on a plant designed in 1960s where technologies like reinjection were not yet developed. Therefore, with reinjection of geothermal fluids environmental pollution from fluids is significantly reduced.

\subsubsection{Land Subsidence}

Land Subsidence is another negative environmental effect of geothermal energy use. According to Oduor (2010) in geothermal exploitation the rate of geothermal fluid extraction is usually greater than the rate at which it is naturally replenished during power plant operation phase. These causes reduced reservoir pressure which cause caving- inn. This phenomenon is called subsidence is mainly caused by:

i.) Pressure drops in the reservoir

ii.) Existence of highly compressible rock formation

iii.) Presence of permeability paths between the reservoir and ground surface

The greatest recorded subsidence was recorded at Wairakei Geothermal Station in New Zealand and had a rate of $13 \mathrm{M}$ per year. Subsidence can be reduced by reinjection of geothermal fluids.

\subsubsection{Soil Contamination}

Geothermal emissions, both gaseous and liquid contaminants end up in the ecosystem and affect plant and animal systems through contaminated soil. The Geothermal fluid disposed of on the soil surface happens to be rich in contaminants that contaminate the soil and hence have negative ecological effect.

\subsubsection{Well Blow Out}

This takes the form of visual and noise pollution. Well blowout is uncontrolled escape of geothermal fluid during drilling of wells where high pressure is encountered. This can be controlled by close pressure monitoring and cementing (Oduor, 2010).

10.1.6. Steam Galleries 
The construction of pipelines for steam evacuation from wells and geothermal auxiliary plant and equipment like cooling towers cause obstruction to plant life by interfering with mobility and visibility. However, if well planned and managed the scenic views may as well lead to favorable results as in the case of Lardevello, Italy where the pipelines and power plant auxiliaries like cooling towers have become part and parcel of tourist attractions, hence positive effect (Berrizbeitia, 2014; Mwangi, 2010; Oduor, 2010).

\subsubsection{Aesthetic and Visual Impact}

Development of geothermal power plants in tourist setups and human settlements causes visual obstructions and interference if not properly done. Whereas the visual impact is temporal in nature during drilling and constructions, it assumes a permanent nature once the plant stats operation and maintenance (Oduor, 2010).

\subsubsection{Solid waste Pollution}

Geothermal development generate significate quantities of wastes like drilling mud, petroleum products like greases, cements, cooling tower sludge which may also be contain mercury.

\subsection{Social-economic Impact of Geothermal}

Geothermal development quite often raises the expectation of; local community, local government, developing agencies, civil society organizations and other stakeholders (Odour, 2010). Geothermal energy development leads to increased economic activity in often remote and rural areas where these resources are found. There is however concern on the need to develop geothermal energy in places with wildlife conservancies and parks and hence the need to understand the effect on wildlife and tourism which is equally beneficial to local and national economies. These leads to conflict of interest between growth of tourism and energy. In Kenya Olkaria geothermal field is located right inside a national part and development often leads to conflict with local Maasai community who are traditionally pastoralist (Berrizbeitia, 2014; Odour, 2010). Other impacts are;

\subsubsection{Water consumption}

Geothermal power development comes with significant water use which should be planned for otherwise it may strain available water supply. Water is used during drilling, construction, powerhouse makeup water, and other activities that arise including human consumption (Clark, Sullivan, Harto, Han, \& Wang, 2012; Oduor, 2010).

\subsubsection{Labor and employment}

Geothermal development requires manpower, machines and materials for project execution. The skills required are both skilled and unskilled. This economically rejuvenates rural communities and hence economic growth. Upon construction and commissioning of plant, permanent and temporary jobs will be created either directly serving in power plants or offering services like cleaning and property guarding which are generally subcontracted (Mwangi, 2010; Oduor, 2010).

\subsubsection{Education}

Power plants often invest in local communities by starting and sponsoring public schools and offering scholarships to local community (Mwangi, 2010; Oduor, 2010).

\subsubsection{Transport and roads}

Geothermal energy sites are often located in remote areas with little or no transport infrastructure. Geothermal development companies often develop access roads which also benefit the local population. In Kenya, Kenya Electricity Generating Company offers free transport to local community members to and from Naivasha town (Mwangi, 2010; Oduor, 2010).

\subsubsection{Health}

The rural communities near geothermal source often have poor access to health services. Investing in polluting geothermal development will only compound the problem. As a result, geothermal development companies like Kenya Electricity Generating Company. Have been building and equipping local health facilities besides ensuring the processes are less polluting to the environment (Mwangi, 2010; Oduor, 2010).

Therefore, from the ongoing discussion of environment and social impact of geothermal development, effort should be made to identify possible hazards and mitigate them. Relevant legislation and proper enforcement can also go far in managing negative effects. By undertaking community social responsibility, geothermal development and exploitation can leave a positive mark to the surrounding community.

\subsubsection{Local cultural values}

Geothermal development comes along with workers from other areas to work in remote sites Bw'Obuya (2002). These workers come along with their own cultural values which may be in conflict with local culture, which is a potential for conflict.

\subsection{THE WELLHEAD TECHNOLOGY VERSUS CONVENTIONAL POWERPLANT}

Geothermal energy is generated when steam from the earth crust is used to rotate turbines of power generators. The steam is ejected through drilled wells sometimes up to more than three kilometers deep into the ground. Several wells must be drilled to supply enough steam to support a conventional geothermal power plant. This process takes very many years to drill enough wells. The wellhead technique was just but an experiment, and it turned out to be a very good way of generating power from wells that 
would otherwise have remained idle for years. In its quest to generate more reliable, climate-friendly electric energy, Kenya has become the first country in the world to make use of temporary geothermal wellheads for grid power, and are currently injecting over 56 megawatts into the national grid. Kenya is therefore the first country in the world to generate geothermal power directly from wellheads (Rojas, 2015).

This development is an indicator that the wellhead technology may be a disruptive technology in geothermal power generation. As investors and researchers take note of this development in Kenya, this technology may soon be adopted by other investors and researchers in geothermal power development not as a temporary measure as it is today, but an alternative to the very expensive and time consuming conventional geothermal power plant development. But for these to happen, research on technical, financial, social and environmental feasibility needs to be carried out.

Green Energy Group (GEG) has designed and delivered 15 wellhead plants to Kenya Electricity Generating Company Ltd. (KenGen.) in the past 4 years that provide a total output capacity of more than $81 \mathrm{MW}$. This represents some $12 \%$ of the entire installed geothermal power generation capacity of Kenya as of 2017. GEG developed mobile and modular substations to help KenGen bring the plants online more quickly. GEG has delivered 6 substations to KenGen, two modular substations and four mobile substations. Idle. GEG's technology has dramatically reduced the time of plants coming online for KenGen to increase supply more quickly for growing demands in the region (Flitcher, 2017).

According to Kenya Electricity Generating Company (KenGen) (n.d.) permanent geothermal power plants take between 24 to 36 months to construct and commission with more time being taken $\mathrm{n}$ to drill wells for steam extraction hence more time is needed in upfront steam field development. The well head power plant on the other hand takes about 6 months hence a provides quick return on investment. Through wellhead technology, it is also possible to the steam wells while producing electricity that can be connected to electricity grid. This facilitates early generation within as short a time as 70 days upon commencing well drilling. Figure 18 bellow shows an assembly of a simple wellhead power plant.

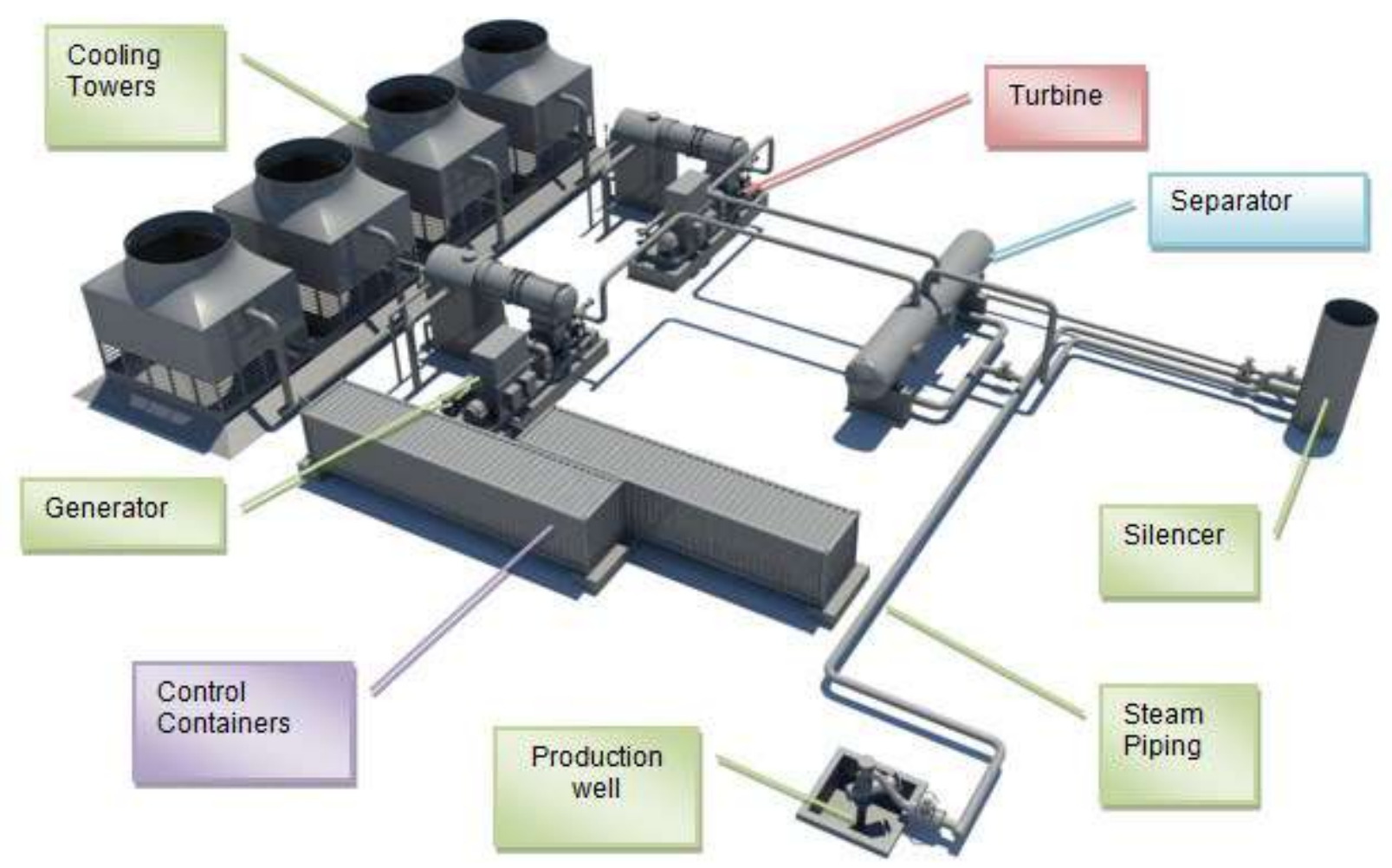

Adopted from Imaida (2017).

Figure 18: A geothermal wellhead plant

Figure 18 illustrates a geothermal wellhead plant with main elements being cooling towers, generator, steam turbines, silencer, separator, and production well and steam piping.

The use of wellhead plants will shorten the waiting period to start generating electricity upon successful drilling of a geothermal production well. It can also be used to supply electricity to the field development activities hence reducing drilling costs besides early revenue streams if connected to the grid. The wellhead technology takes advantage or capitalizes on the idle steam resource 
time between completions of the steam well which then is usually plugged and the completion of the central or conventional geothermal power plant meant to use the idle wells.

\subsection{Design and Construction of Wellhead Plant}

Elements of the wellhead plant

According to Imaidi (2017), the layout of wellhead plant is comprised of the following components:

i.) Steam gathering system components that include the wellhead assembly, the working valve, two phase delivery piping, moisture separator, brine disposal system, pressure control system, brine level control system, a silencer or rock muffler and saturated steam delivery piping to the turbine.

ii.) A small single flash, backpressure or binary turbine generator unit, and its ancillaries.

iii.) A compact cold end, comprising of surface, direct contact or air-cooled condensers, hot well pump, cooling towers, cooling water circulation pump, a collector sump and associated control systems.

iv.) Non-condensable gas extraction system that can be a pure ejector, vacuum pump or hybrid system.

v.) A compact switchgear and control room in a container or compact permanent structure.

vi.) A standard centralized or compact switchyard on a portable skid and transmission line.

\subsection{Benefits and Limitations of Geothermal Wellhead Plants}

There are various benefits from use of geothermal power plants according to Wada, Maedomari, \& Furuya, (2017) and Imaidi

(2017). These include;

\subsubsection{Benefits}

i.) Where we have tough environmental restrictions like Japan where most of geothermal fields are in protected National parks with restricted land use, geothermal wellheads are a solution. An example is the Waita geothermal power plant in Kumamoto Prefecture, Japan. This is a $2 \mathrm{MW}$ geothermal power plant within an ordinary district of the National Park, where the Ministry of the Environment requested the concrete foundation area of the site should be less than $200 \mathrm{~m}^{2}$, which could achieved by adopting a flash type steam turbine and generator, a compact condenser, a cooling tower and so on .

ii.) Wellhead plants are extremely relevant where cites have extremely stringent transport restrictions and installation requirements, equipment transportation and installation work could be completed successfully.

iii.) Wellhead plants can be used to generate electricity effectively by using saturated steam from $120^{\circ} \mathrm{C}$ to $200^{\circ} \mathrm{C}$ class which is not used even if it is injected in various hot springs.

iv.) Low transmission costs since it can be connected to a nearby low voltage utility pole, unlike in the case of a largescale plant, it is necessary to build a steel tower for high-voltage power transmission.

v.) The plants are relatively easy to operate and control during generation.

vi.) Huge Investment Opportunity Wellhead generators provides a big opportunity to power developers, utilities and independent power producers to significantly cut capital costs and shorten the time between exploration and revenue generation in geothermal projects. The wellhead generator can be used to test the geothermal field and in effect benefit from data already gathered.

vii.) There is no need for another power source to start portable wellhead generators and can be started without any auxiliary power source except a battery for instrumentation the unit has steam turbine driven oil pump and mechanical-hydraulic control system. Therefore the unit can be installed without considering any electric network of the area.

viii.) Attracting Investment The units enable developers, utilities and independent power producers to significantly shorten the time between exploration and revenue generation in geothermal projects and thereby accelerate the growth in the geothermal development in Kenya.

ix.) Optimal Energy Utilization The independent wellhead power plant unit enables optimum power to be produced from each individual well regardless of their differing outputs and characteristics. The concept negates the needs of traditional power plants for well redundancy or an excess steam buffer to cater for well failures and allows all wells to be utilized. The wellhead generating unit is modular in design also makes it possible to generate electricity from remote wells that are outside the topographical reach of large traditional plants

x.) Rapid Deployment Portable Wellhead generator modular design, based on standard manufactured components, allows for significantly reduced lead times and early power online. Today, manufacturers can deliver power online within 12 months of ordering the portable modular wellhead power plant and thereafter rapid deployment, at a rate of one modular portable wellhead unit plant per month, can be achieved 
xi.) Reduced Cost per Megawatt The unit modular design like C64 from the Green Energy Group can generate over 6.4 MW (based on standard manufactured components; this enables a highly competitive capital price and allows for easy maintenance and access to spare parts. By focusing on the characteristics of each well independently, this module is able to adjust turbines to achieve a high level of power output efficiency, driving down electricity production costs.

xii.) Lower Risk With modular flexibility, the wellhead turbine power plant is delivered in standard containers and each module is ready made at the factory allowing for quick installation. It is designed to operate independently for each well, but can be organized in power farms to provide a similar power output to large traditional geothermal power plants. In the event of a well failure, the module is designed to be decommissioned, transported and redeployed on a second well, maximizing the return on investment. Equally importantly, the failed well can be returned to its original state thus preserving the environment.

\subsubsection{Limitations of Wellhead plants}
i.) As a new technology, wellhead equipment is still relatively high
ii.) Typically, each well requires a wellhead generator hence many of them are required for a given steam field which brings challenges in operation and maintenance.
iii.) Use of wellheads comes with challenges of handling brine and effluents from the plant hence environmental issues arise
iv.) Use of wellheads requires many transformers and transmission networks from a give geothermal field.

\subsection{DISCUSSION AND RECOMMENDATION AND CONCLUSION}

\subsection{Challenges and Opportunities in Geothermal Power Generation}

Geothermal growth and development of electricity generation has increased significantly over the past 30 years approaching $15 \%$ annually in the early part of this period and dropping to $3 \%$ annually in the last ten years due to an economic slowdown in the Far East and the low price of competing fuels as well as several challenges including long periods required to develop new power plants. Direct-use has remained steady over the 30 -year period at $10 \%$ growth annually. Most of the increase has been due to geothermal heat pumps. At the start of this 30-year period, only ten countries reported electrical production and/or direct utilization from geothermal energy. By the end of this period, 72 countries reported utilizing geothermal energy. This is over a seven-fold increase in participating countries. At least another 10 countries are actively exploring for geothermal resources and should be online by 2010 .

Developments in the future will include greater emphases on combined heat and power plants, especially those using lower temperature fluids down to $100^{\circ} \mathrm{C}$. This low-temperature cascaded use will improve the economics and efficiency of these systems, such as shown by installations in Germany, Austria and at Chena Hot Springs, Alaska. Also, there is increased interest in agriculture crop drying and refrigeration in tropical climates to preserve products that might normally be wasted. Finally, the largest growth will include the installation and use of geothermal heat pumps, as they can be used anywhere in the world, as shown by the large developments in Switzerland and Sweden.

At community level, particularly rural settlements in both developed and developing countries that provision of cheaper and environmentally friendly power, economic growth and creation of employment opportunities are some of the key benefits of geothermal energy utilization

From literature, it is posited that the problem facing geothermal development for electricity production is the huge exploration and high investment costs and even when steam is discovered in wells, it takes very many years to develop a power plant because it takes long to drill sufficient number of wells to generate sufficient steam to support a conventional power plant. It is also observed that half the capital cost in developing a geothermal power plant goes to the steam field development. To avoid the case where wells with steam are kept waiting for years to develop a power plant, a wellhead can be placed on individual wells to generate power as more wells are drilled. When enough wells and steam is developed, wellheads are removed to interconnect the steam from different wells to develop a conventional geothermal power plant. In this research, feasibility of retaining wellheads as permanent installation to substitute conventional power plants will be investigated. This indeed will make Wellhead technology a disruptive technology in geothermal electric power generation because it will mean the capital cost is reduced by close to half besides having early electricity from individual wells.

The local community play a critical role in successful and smooth execution of geothermal projects. The local community have a vital role in environmental management and development and need to be involved in the entire project. Residents often have different expectations and positions concerning geothermal projects. Ultimately some will support, others will oppose while others will place conditions for them to support the project. To reduce resistance to the project, public relation exercises should be undertaken right from the project conception stage through presentations to all stakeholders. During project implementation period information should be disseminated on progress. Through environmental impact assessment, environmental concerns will be 
identified, and mitigation measures put in place. During project development as well us during the entire life of the plant, the project should add or create local benefits to the community. Where necessary, compensation should be done fairly to individuals and groups for any property damaged or acquired to facilitate the project (Cataldi, 2001).

According to Journey (2015) public opinion and approval should never be taken for granted since there is evidence that if information is given approval rating is increased but perceived risks associated with geothermal or related activities can lead to rejection of a project.

\subsection{Geothermal Opportunities, Issues and Challenges \\ 12.2.1. Opportunities}

Several developments continue to lay ground for accelerated growth of geothermal energy. These according to Younger (2015) include;

i.) There is increasing public awareness and appreciation of geothermal energy as a renewable energy resource

ii.) There are advances in modelling and characterization of leading to better management of shallow and low enthalpy geothermal resources

iii.) Advances in drilling technology and management have led to reduced upstream costs of a geothermal project

iv.) Development in reservoir characterization techniques have led to better estimation of geothermal reservoir geometry and properties hence more success rates in drilling

v.) Development of directional as opposed to vertical drilling has increased yield and success rates.

vi.) Geothermal has more positive environmental benefits compared to fuel based power plants.

According to William et al. (2001), geothermal power projects have advantages from an environmental viewpoint with low carbon footprint, no external fuel sources, transportation or processing, disposal, and storage, and the ability to dispose of unwanted by-products back underground.

\subsection{Main Challenges Facing Geothermal Development}

a.) Technical and Environmental Challenges

Main Issues of Possible Concern in Geothermal Projects are;

i. Restrictions in the use of areas and properties due to land occupation, field crossings deforestation, excavations, modification of paths, construction of roads and power plants.

ii. Levelling of working areas to construct drilling yards, store equipment and materials, and erect plants hence interference with geography and topography of activity areas.

iii. Noise resulting from circulation of heavy trucks, drilling-rig motors, geothermal well testing, fluid production, and other field engineering and non-engineering processes during exploration and drilling.

iv. Disposal of waste materials during and after completion of drilling e.g. mud, cuttings, oil, and fluids of different nature used in processes.

v. Uncontrolled blowouts of wells under pressure.

vi. Scaling pipes and other surfaces as a result of leakages of hot water, water-steam mixtures, and condensate from turbines.

vii. Soil pollution due to percolation of salts into water streams and the soil contamination

viii. Discharge of spent water into ground, water courses, lakes and lagoons, after their separation from steam;

ix. Injection of condensate and waste water into fresh aquifers hence causing pollution.

x. Gaseous emission into the atmosphere by carbon dioxide, hydrogen and steam containing toxic elements like mercury, azimuth, boron.

xi. Acid rains in environment due to gaseous emissions like Sulphur dioxide, Nitrous oxides and carbon dioxide emissions from operations including combustion of fuels during field development and drilling.

xii. Induced seismic activities due to water injection to wells.

xiii. Surface subsidence or sinking due to lowering reservoir pressure as result excessive of fluid as witnesses at Wairakei power plant in New Zealand.

xiv. Heat pollution, particularly in the areas around the power plants.

xv. Visual impact on landscape due to trenches, platforms, drilling-rigs, barracks, sheds, water pipes, steam pipes, plants equipment, industrial buildings, power lines, and other structures.

xvi. Cauterization of drilling yards due to use of cements in drilling and other engineering applications.

It is through both subsurface and power plant technologies that environmental challenges of geothermal development are address. Research and development into new, efficient and cost-effective technologies will enhance safety and environmental integrity with respect to geothermal energy and electricity development. 


\section{b.) Social Challenges}

A geothermal project like other major projects needs to win the support of the local community. According to Cataldi (2001), social acceptance is an important requirement to smoothly execute projects. This can be realized by;
i.) Minimizing or avoiding environmental effects
ii.) Avoiding adverse effect on people
iii.) Generating or creating direct benefit for the local community from the project.

\subsection{Recommendations}

\subsubsection{Recommendations to Technical Challenges in Geothermal Development}
i.) Develop open interaction and cooperation to enhance complementary research into geothermal energy
ii.) Develop better standards for monitoring and reporting geothermal operations and resource exploitation
iii.) Mitigate induced seismicity in Engineered geothermal system
iv.) Improve power plant designs
v.) Minimize water use by developing appropriate technologies in project life cycle assessment.
vi.) Develop better prediction techniques for heat flows and ahead of the drilling bit
vii.) Develop better equipment and tools for hard rock so as to enhance EGS technology

\subsubsection{Minimize Adverse Environmental Impacts}
i.) There is neec
resources.
ii.) There is need to develop conversion technologies and design plants that geothermal applications beyond baseload e.g. Allow turbines to operate close to their optimal conditions.
iii.) There is need to minimize undesirable environmental effect by adopting better technologies in the plant lifecycle management.

iv.) Unexpected encounter of supercritical resources often leads to trouble in drilling. It is desirable to know in advance about the existence of this resource to manage supercritical resources. There is need for exploration and imaging technologies prior to drilling, and better reservoir modeling.

v.) Sites for temporary works and permanent plants can be selected as much as possible in correspondence to unused or less fertile areas. The areas used for temporary works can be later restored (or even improved) by planting appropriate vegetation.

vi.) Drilling areas can be minimized by drilling two to five directional wells from the same yard. This will reduce the area covered and hence shorter pipelines with high yield hence at lower cost of steam field development.

vii.) Major noise sources like steam venting, drilling-rig motors, plant machinery, etc. can be greatly reduced by an adequate design and/or by acoustic insulation of the noisiest equipment in a given operation and area.

viii.) Residual waters are usually re-injected into the original reservoir, which enables not only to dispose of undesirable chemicals, but also to prevent or greatly reduce subsidence.

ix.) Occurrence of micro-earthquakes due to injection of spent water can be prevented or greatly reduced by installing an appropriate seismic monitoring network, which makes it possible to keep the amount and pressure of injected water below a critical threshold to be established case by case according to the characteristics of the area.

x.) Cauterization of drilling yards can be prevented by grouting the area around the well-head.

xi.) Uncontrolled blow-outs of wells are prevented by a suitable design of the technical drilling profile, and by using adequately-sized blow-out preventers.

xii.) Pollution of fresh water in shallow aquifers are avoided by casing and thoroughly cementing the wells in correspondence to water-bearing layers.

xiii.) Saline encrustations and residual materials from drilling and well production can be temporarily stored in watertight tanks, until they can be carried to sites with appropriate processing facilities.

xiv.) Condensable and non-condensable gases associated with fluid production can be carefully monitored in both nature and amount to establish whether any of them may generate undesirable effects on people and ecosystem if released into the atmosphere. When no economically-sound solution exists, then dispersing gases into the atmosphere, anemometric surveys are performed to determine the best dispersion method (ventilation or exhausting chimney) and its technical parameters.

xv.) Several methods like Stratford process, BIOX process and others are available for $\mathrm{H}_{2} \mathrm{~S}$ abatement and should be adopted in certain cases. In other cases, when for economic reasons one of these methods cannot be adopted and there is no other solution than discharging $\mathrm{H}_{2} \mathrm{~S}$ into the atmosphere, its noxious effects can be minimized by specially designing the generation plants and by locating them as much as possible in well-ventilated sites and/or scarcely populated areas. 
xvi.) Acid rains and heat dispersion in the areas around the power stations can be minimized by installing the plants as much as possible in elevated and well-ventilated sites.

xvii.) To minimize their visual impact, water and steam pipes can be painted with the prevailing color of the local vegetation or environment.

xviii.) To accommodate in a harmonious way into the landscape the sky-line of permanent plants and facilities, a suitable design of the buildings can be made with the specific objective. Green areas with stairs, flower-beds, and fountains can also be created artificially around these buildings.

\subsubsection{To Minimize Conflict with Community before Implementation}

This can be done through Public relations and information campaign this action may include:

i.) During the planning stage of the intended project: Contacts with public administrators of the area concerned, not only to provide them with information on the project objectives, but also to start having an idea of the people's attitude towards the new initiative Preparation of public opinion through clear and timely information campaign;

ii.) Presentation to regional authorities, public administrators, and important entities of the area,

iii.) Provide brochures outlining the project objectives, the environmental measures in program, and the social benefits that the project is expected to produce.

\subsubsection{Strategies to Get Support during the Implementation Stage of the Project}

i.) Periodical dissemination of information on the activities already completed and in Program through meetings with local administrators, and by means of media.

ii.) Promotion of project related scientific meetings, workshops and conferences in the work area.

iii.) Organizing visits to project sites and plants for local students and other interested people including the leaders and general community members who will turn out as ambassadors for the project to the community.

iv.) Creation in the work area of a demonstration facility, or information centers or community liaison offices equipped with posters, models, photos, and leaflets of the project.

v.) Encouragement to implementation of local development plans and new economic or social initiatives that might have positive impacts onto the project objectives; and Consideration for traditions, culture, and modes of thinking of indigenous communities.

vi.) Creation of local benefits especially when large projects for geothermal electric generation are involved, social acceptance depends on the public perception that the new initiative will bring direct benefits to the residents in the area concerned. To this end, some or all of the following measures can be taken.

\subsubsection{Approaches to creation of local value in geothermal project}

a.) Steady or temporary hiring of native workers if and when opportunities arise.

b.) Subcontracting local firms for supply or execution of as many as possible tasks and material supply as inputs.

c.) Training and employing to the project firm of qualified locals or natives as scientists, engineers and technicians and unskilled work.

d.) Modernize local life when the project is implemented in a remote area, by development of camps for personnel equipped with cafeteria and recreation facilities with subsidized access by the local community.

e.) Supply of free or cheap electricity, steam or hot water for use in public buildings, social centers, and other facilities of public interest to the local community.

f.) Development of public infrastructure projects like road, sewage, round-about, bridges, recreational areas, and others, modified to allow for the installation of project facilities and promotional messages.

g.) Sponsorship of cultural, sports, and community events held in the geothermal project areas.

h.) Offer grants and scholarships to local professionals and students for research, or publication of works on important aspects of local community development perspectives, history, traditions, and culture of the project area.

i.) In alternative to some of the measures above, the allocation of a fraction of the project profits may be negotiated with the local administrators for use in community development projects.

\subsection{CONCLUSSION}

Geothermal energy is renewable energy resource found in the earth's surface with potential for several applications including geo-exchange, direct application and power/electricity generation. With high load factors, geothermal power plants are ideal for base load electricity generation. Geothermal energy systems have proved to have minimal environmental footprint, are not affected by climate change and have potential to become the global cheapest source of sustainable renewable energy with almost 
zero-emissions, and with ability to supply direct thermal use and electricity. With geothermal energy, displacement of more emissive and hence polluting fossil energy supplies like coal, diesel power plants and natural gas is feasible and is so expected to play a crucial role of facilitating both energy security and climate change mitigation. Although, geothermal energy is now considered a mature technology it only realizes growth of 3-4\% per year while global untapped capacity of more than $100 \mathrm{GW}$ while contribution to global electricity production remains less than $1 \%$.

Geological factors make it impossible for some countries or geographical locations to realize geothermal energy. Slow growth is due to natural disasters in some countries, permitting and regulatory problems and processes, cheap fossil fuels as alternatives and limited access to financing and general nature of available technologies. Effort should be made to increase the rate at which this significant potential is tapped into for greater contribution to electricity mix globally. Technologically hydrothermal geothermal systems with wells down to $2-3 \mathrm{~km}$ provides a mature technology, enhanced geothermal systems at 3-5 km depth provides new technology while supercritical systems at 5-10 km depth are a future technology in geothermal development. Wellhead technology currently provide a quick access to geothermal electricity ahead of full development of a conventional power plant as demonstrated by several operating wellhead plants in Olkaria steam fields in the Kenyan Rift Valley.

The attitude of local communities at geothermal project areas significantly influences success rates of the project. Strategies used to obtain acceptance, agreement, or at least the tolerance of the project by the people residing in the project area also called social acceptance, or social consensus of the project include, prevention of adverse effects on people's health, minimization of environmental impact, and creation of direct benefits for the resident communities. During project execution, effort should be made to create local social benefits to the community like employing locals and providing incentives to the community through sponsoring community projects and infrastructure. Legal framework can be put in place to enforce environmental, health and safety issues related to geothermal energy development and exploitation. Close monitoring and control of environmental issues and effective social responsibility initiatives can be used to mitigate negative environmental and social effects of geothermal development.

To realize faster growth, commitment by individual countries will see growth in geothermal power as shown by countries like Kenya, Iceland, Salvador and New Zealand where there is serious commitment to adoption of geothermal power with over $20 \%$ of electricity coming from geothermal which is well above the average global contribution. As far as environment and safety is concerned, it is through both subsurface and power plant technologies that environmental challenges of geothermal development are addressed. Research and development into new, efficient and cost-effective technologies will enhance safety and environmental integrity with respect to geothermal energy and electricity development. Geothermal energy resources are significant and if the technical, financial, environmental, social and logistical challenges are addressed, it can be a major player in global energy and electricity market as renewable, safe and cheap sources. Research and development of technology and solutions to current challenges should be enhanced. Drilling which is a critical process in geothermal resource exploration and development is expensive, and therefore development of geophysical methods to resolve this problem is highly desirable as it could significantly reduce the cost of geothermal energy development. Advanced technology in drilling and upfront activities will reduce costs and risks in development. Generally, a geothermal power plant project goes through exploration or prefeasibility stage, drilling (feasibility) stage and development (production wells, reinjection wells, steam gathering system and power plant construction and commissioning) followed by operation and maintenance of the plant before the plant is finally retired. This cycles take relatively long and there is need to improve or optimize them. The use of wellhead plants in the project will reduce the waiting time to start realizing electricity from the geothermal resource. Additionally power plant conversion technologies and reservoir engineering and management will increase output and efficiency in electricity generation from various geothermal resources. Therefore, from the foregoing discussion, this study concludes that technical barriers and challenges, high financial costs and long gestation periods prevent faster development of geothermal electricity.

\subsection{REFERENCES}

African Development Bank (n.d.). Expanding geothermal development in Kenya: a model for replication. Retrieved from https://www.afdb.org/en/projects-and- operations

Bertani, R. (2015). Geothermal Power Generation in the World 2010-2014 Update Report. Geothermics. Retrieved from

https://www.scribd.com/doc/315732925/Geothermal-power-generation-in-the-world-20102014-update-report

Berrizbeitia, L.D. (2014). Environmental impacts of geothermal energy generation and utilization. Retrieved from

https://geothermalcommunities.eu/assets/elearning/8.21.Berrizbeitia.pdf

BP, (2017). Geothermal power. Retrieved from

https://www.bp.com/en/global/corporate/energy-economics/statistical-review

Bradley, J. (2016, August 24). A history of Geothermal. Cleanenergy Ideas. Retrieved from 
https://www.clean-energy-ideas.com/geothermal/geothermal-energy/history-of-

Bw'Obuya, N.M. (2002). The socio-economic and environmental impact of geothermal energy on the rural poor in Kenya

https://geothermalcommunities.eu/assets/elearning/8.24.Geothermal\%20on\%20Economics $\% 20$ in\%20Kenya.pdf

Cataldi, R. (2001). Social acceptance of geothermal projects: problems and costs. Retrieved from https://www.geothermal-energy.org/pdf/igastandard/iss/2001 romania/cataldi.pdf

Chiasson, A.D. (2016). Geothermal heat pumps and heat engine systems: Theory and practice. West Sussex, UK: John Wiley and Sons

Curtin University. (n.d.). Research data management: Data description. Retrieved from http://libguides.library.curtin.edu.au/c.php?g=202401\&p=1333152

Clark,C., Sullivan,J., Harto,C.,Han, J., and Wang, M. (2012). Life cycle Environmental impacts of geothermal systems. Argonne National Laboratory. Retrieved from https://geothermalcommunities.eu/assets/elearning/8.11.Clark.pdf

Dickson, M.H. Fanell, M. (2003). Geothermal energy: Utilization and technology. ENESCO Publishing. Retrieved http://unesdoc.unesco.org/images/0013/001332/133254e.pdf

Dickson, M.H. \& Fanelli, M. (2003). Geothermal energy: Utilization and technology. Paris; United Nations Educational, Scientific and Cultural Organization

DiPippo, R. (1999, June). Small geothermal power plants: Design, performance and Economics.GHC Bulletin. Retrieved from https://geothermalcommunities.eu/assets/elearning/7.10.art1.pdf

Di Pippo, R. (2012). Geothermal power plants: Principles, applications, case studies and Environmental impact, $3^{\text {rd }}$ Edition, Oxford, UK: Elsevier

DiPippo, R. (2016). Geothermal Power Generation: Developments and Innovation. London: Woodhead Publishing, 2016. 854 pages. ISBN: 9780081003374 cloth.

Geothermal Energy Association (2014). Geothermal energy. Retrived from http://geo-energy.org/basics.aspx

Geothermal Energy Association (GEA) (2016). 2016 Annual U.S. \& Global Geothermal Power Production Report, GEA. Retrieved from http://geo-energy.org/reports/2016/2016\%20Annual\%20US\%20Global\%20Geothermal\%20 Power\%20Production.pdf.

Geirdal, C. (2013). Economic comparison between a wellhead Geothermal Power plant and traditional Geothermal Power plant. Retrieved from https://skemman.is/.../Economic\%20Comparison\%20between\%20a\%20Wellhead\%20Ge.

European Union. (n.d.). Overcoming Research Challenges for Geothermal Energy. Retrieved from Retrieved from https://setis.ec.europa.eu/energy-research/sites/

Flitcher, A. (2017, May 22). Kenya driving development with GEG geothermal wellhead Plants. Retrieved from http://www.thinkgeoenergy.com/kenya-driving-development

Goldstein, B. A, Hiriart, G., Tester, J., B., Bertani, R., Bromley, V. I. Zui, V.I. (2011). Great expectations for geothermal energy to 2100. Retrieved from https://pangea.stanford.edu/ERE/pdf/IGAstandard/SGW/2011/goldstein1.pdf

Grassley W.E. (2010). Geothermal energy: renewable energy and the environment. Boca Raton: CRC Press. Retrieved https://www.crcpress.com/Geothermal-Energy-Renewable-Energy- and-the- Environment-Second-

Edition/Glassley/p/book/9781482221749

Gurgencil, H., Rudolph, V., Saha, T, and Max Lu, M. (2008). Challenges for geothermal energy utilization. Retrieved from pangaea.stanford.edu/ERE/pdf/IGAstandard/SGW/2008/gurgenci.pdf

Kenya Electricity Generating Company. KenGens Wellhead technology. Retrieved from http://www.kengen.co.ke/content/kengens-wellhead-technology

Khemani, H. (nd.) Advantages of Geothermal Power Plants. Advantages of Using Geothermal Energy for Producing Electricity. Retrieved from

https://www.brighthubengineering.com/power-plants/6164-advantages

-of-geothermal-power-plants/ 
Huttrer, G.W. \& Moletto (nd). Benefits of geothermal power. Retrieved from http://www.oas.org/reia/geo-caraibes/PDF\%20Documents/Presentations/Technical\%20$\% 20$ Geothermal\%20Intro\%20(Huttrer\%20and\%20Miletto).pdf

International Energy Agency (IEA) (2017). Geothermal energy. IEA. Retrieved from https://www.iea.org/topics/renewables/geothermal/

IRENA (International Renewable Energy Agency) (2017a). Featured Dashboard - Capacity Generation. Reprieved from http://resourceirena.irena.org/gateway/dashboard/?topic=4\&subTopic=16.

IRENA (International Renewable Energy Agency) (2017b). Renewable Cost Database. Retrieved from http://costing.irena.org/irena-costing.aspx.

Odour, J.A. (2010). Environmental and Social Considerations in Geothermal Development. Retrieved from https://geothermalcommunities.eu/assets/elearning/8.15.ts01e_ts01e_oduor_3857.pdf

Laureate Education (Producer). (2012b). Choosing your doctoral topic [Video file]. Baltimore, MD: Author.

Mulaha, T. (2013). On overview of Geothermal Resources Development in Kenya. Retrieved from https://www.esmap.org/sites/esmap.org/files/3-20Timothy\%20Mulaha_Kenya.pd

National Renewable Energy Laboratory (NREL) (nd). Geothermal Electricity Production Basics Retrieved from https://www.nrel.gov/workingwithus/re-geo-elec-production.html

Nelson, A. (2017) 2017 Outlook: Geothermal Is Trending Upwards. Retrieved from https://www.renewableenergyworld.com/articles/print/volume-20/issue

North Carolina State University (n.d.). Defining Research Data: Data Management. Retrieved from https://www.lib.ncsu.edu/data-management/define

Renewable Energy World (2016). Geothermal Power and Electricity Production Retrieved from https://www.renewableenergyworld.com/geothermal-energy/

Rojas, F. (2015, 21 October). Geothermal wellhead power plants are proving to be a faster way to develop new energy projects in Kenya. Inter Press. Retrieved from http://www.thinkgeoenergy.com/wellhead-geothermal-plants-are-a-key-pillar-of-kenyas

Richter, A. (2017, February 1). Overview on installed geothermal power generation capacity Worldwide. ThinkGeoenergy. Retrieved from http://www.thinkgeoenergy.com/overview-on-installed-geothermal-power-generation-

Richter, A. (2018, February 19). Geothermal energy in Europe and the rest of the world. Think Geoenergy. Retrieved from http://geoop.dk/wp-content/uploads/2018/02/ThinkGeoEnergy_AlexanderRichter.pdf

Ritcher, A. (2019, January 2019). Global geothermal power generation capacity reaches 14, 600 MW. ThinkGeoenergy. Retrieved from

http://www.thinkgeoenergy.com/global-geothermal-power-generation-capacity-reaches14600-mw-at-year-end-2018/

Rinkesh, (n.d.). History of Geothermal energy. Retrieved from https://www.conserve-energy-future.com/geothermalenergyhistory.php

Shere, J. (2013). Renewable: The World-Changing Power of Alternative Energy. St Martin's Press: New York.

Sigfusson, B. \& Uihlein, A. (2015). 2015 JRC Geothermal Energy Status, Retrieved from https://setis.ec.europa.eu/sites/default/files/reports/ 2015_jrc_geothermal_energy_status_report.pdf

Simiyu, S. (2010). Status of Geothermal Exploration in Kenya and Future Plans for Its Development. Retrieved from https://orkustofnun.is/gogn/unu-gtp-30-ann/UNU-GTP-30

Holm, A., Jennejohn, D., \& Blodgett, L. (2012, November). Geothermal energy and Greenhouse gas emissions. Geothermal energy association. Retrieved from http://geo-energy.org/reports/GeothermalGreenhouseEmissionsNov2012GEA_web.pdf

Horne, R.N. (2011). What does the future hold for geothermal energy? Retrieved from https://www.geothermal-energy.org/pdf/IGAstandard/NZGW/2011/K1.pdf

Intergovernmental Panel on Climate Change (IPCC) (2009, December 22). Chapter 4: Geothermal 
Energy. Retrieved from

https://www.ipcc.ch/pdf/special-reports/srren/drafts/SRREN-FOD-Ch04.pdf

Idaho National Laboratory (2006, November). The future of geothermal energy. MIT. Retrieved

From https://energy.mit.edu/wp-content/uploads/2006/11/MITEI-The-Future-of-

Geothermal- Energy.pdf

Imaidi, D.L. (2017). Analysis of maintenance methods and developing strategies for optimal Maintenance of wellhead power plants at Olkaria Geothermal field in Kenya. Retrieved from https://orkustofnun.is/gogn/unu-gtp-report/UNU-GTP-2017-12.pdf

International Renewable Energy Agency (IRENA). (2017, September). Geothermal power technology brief. IRENA. Retrieved from

https://www.irena.org/-

/media/Files/IRENA/Agency/Publication/2017/Aug/IRENA_Geothermal_Power_2017.pdf

IRENA (2017), GeiNTERANTIONAL Energy geothermal Power Technology Roadmap:

Technology Brief, International Renewable Energy Agency,

International Energy Agency (IEA) (2012). Technology mapwork: Geothermal heat and power.

IEA. Retrieved from

https://www.iea.org/publications/freepublications/publication/

Karytsas, C. \& Mendrinos, D. (2013, June). Global Geothermal Power Market. European

Geothermal Congress, Pisa Italy. Retrieved from

https://www.researchgate.net/publication/258926033_

Global_Geothermal_Power_Market

Kollikho, P. \& Rivard, B. (2013). Harnessing geothermal energy: The case of Kenya. The Climate and Development Knowledge Network. Retrieved from https://cdkn.org/wp-content/uploads/2013/01/Kenya_InsideStory-Pr3Final_WEB1.pdf

Lund, J. (2009). Characteristics, development and utilization of geothermal resources.

ResearchGate. DOI: 10.1007/978-3-540-75997-3_13. Retrieved from

https://www.researchgate.net/publication/226005395_Development_and_Utilization

Lund, J. W., Bertani, R. \& Tonya L. Boyd, T.L. (2015). Worldwide Geothermal Energy Utilization. GRC Transactions, 39, 79-92. Retrieved from http://pubs.geothermal-library.org/lib/grc/1032136.pdf

Lund, J., Sanner, B., Rybach, L. R. Curtis. \& Hellström, G. (2004, September).Geothermal (ground-Source) heat pumps a world overview. GHC Bulletin. Retrieved from https://www.researchgate.net/publication/238065306_Geothermal_ground_source

Matek, B. (2016, March). 2016 Annual U.S and global geothermal power production report. Geothermal Energy Association. Retrieved from http://geoenergy.org/reports/2016/2016\%20annual\%20us\%20global\%20geothermal\%20 power\%20production.pdf

Monterrosa, M. (2009). Planning of Geothermal Projects: A Case Study on Central America. Retrieved from Https://Orkustofnun.Is/Gogn/Unu-Gtp-Sc/UNU-GTP-SC-09-12.Pdf

Mwangi, N.M. (2010). Environmental and socio-economic issues of Geothermal Development in Kenya. Retrieved from https://geothermal.org/PDFs/Articles/10MarApril24.pdf

Mburu, M. (2012). Geothermal energy utilization. United Nations

University. Retrieved from https://orkustofnun.is/gogn/unu-gtp-sc/UNU-GTP-SC-15-0204.pdf

Muffler, L.J.P. and Cataldi, R. (1978). Methods for Regional Assessment of Geothermal Resources.Geothermics, 7, 3-89. http://dx.doi.org/10.1016/0375-6505 (78)90002-0

North Alberta Development Council (2019, February). Northern Alberta geothermal potential Mapping Project - Final Report. Retrieved from https://nadc.ca/media/17703/1-final-report-with-cover-page.pdf

Popovski, K., (2003). Geothermal Energy for Agriculture, International Workshop of Swiss Geothermal Association, Luzern, Switzerland

Rees, S.J. (2016). An introduction to ground-source heat pump technology. Retrieved 
from https://www.researchgate.net/publication

1303413192_An_introduction_to_ground-source_heat_pump_technology

Reinsch1, T., Dobson, P., Asanuma, H., Huenges, E., Poletto, F. \& Sanjuan, B. (2017).

Utilizing supercritical geothermal systems: a review of past ventures and ongoing

research activities. Reinsch et al. Geotherm Energy, 5(16), 1-25.

doi.10.1186/s40517-017-0075-y

Richter, A. (2018, February). Geothermal energy in europe and the rest of the world.

Think Geoenergy. Retrieved from

http://geoop.dk/wp-content/uploads/2018/02/ThinkGeoEnergy_AlexanderRichter.pdf

Rowley, P. (2016, November 9). Magma Power: how superheated molten rock could provide renewable energy. Elsevier. Retrieved from

http://scitechconnect.elsevier.com/magma-power-superheated-molten-rock-energy/

Stone, A.M. (1980). Geothermal energy -an overview. Hamlet, 1(2) 78-88. https://www.jhuapl.edu/techdigest/views/pdfs/v01_n2_1980/v1_n2_1980_stone.pdf

Schwartz, A. (2011, February 17). Volcanic magma could provide geothermal energy. Fast Company. Retrieved from

https://www.fastcompany.com/1728785/volcanic-magma-could-provide-geothermal-energy

Sutter, J., Kipyego, E., \& Mutai, D. (2012). The use of portable geothermal wellhead generators as small power plants to accelerate geothermal development and power generation in Kenya. GHC Bulletin .Retrieved from. Retrieved from https://pdfs.semanticscholar.org/2ccf/ea5912930aa49a2246d235105cbaacb7672b.pdf

Tenzer, H., (2001, December). Development of Hot Dry Rock Technology-Heat Center Quarterly Bulletin, 22, (4). 14-22

Retrieved from https://www.osti.gov/servlets/purl/1209249

Tsuchiyaa, N. \& Yamadab, R. (2017). Geological and geophysical perspective of supercritical Geothermal energy in subduction zone, Northeast Japan.

Procedia Earth and Planetary Science 17, 193 - 196. Retrieved from https://pdfs.semanticscholar.org/1b0f/2784b0eb1428896a2a60d36c73a91dd30083.pdf

Tosha, T., Shimada, T., \& Nakashima, H. (2017). The Research and Development for the Geothermal Energy in JOGMEC, Japan. Retrieved from https://pangea.stanford.edu/ERE/db/WGC/papers/WGC/2015/11085.pdf

Ugwu, S. A. \& Nwosu, J. I. (2009). Detection of Fractures for Groundwater Development in Oha Ukwu using electromagnetic profiling. Journal of Applied Science and Environment Management (13)4, 59 - 63 Retrieved from http://www.bioline.org.br/pdf?ja09059

Ungemach, P., Antics. M., \& Papachristou, M. (2005). Sustainable Geothermal Reservoir Management. Proceedings World Geothermal Congress 2005 Antalya, Turkey, 24-29

April 2005

https://www.geothermal-energy.org/pdf/IGAstandard/WGC/2005/0517.pdf

US Department of Energy (2017). Subsurface Technology and Engineering Research, Development, and Demonstration (SubTER) Crosscut https://www.energy.gov/sites/prod/files/2017/04/f34/SubTER\%20Fact\%20Sheet\%20042017. pdf

US Energy Department (2017). 2017 Annual Report. Retrieved from htps://www.doi.gov/sites/doi.gov/files/uploads/doi_fy2017_afr.pdf

US Department of Energy (nd). Geothermal energy. Retrieved from https://www.energy.gov/sites/prod/files/2014/06/f16/geothermal_energy.pdf

US Energy Information Administration (2017, November 18). Geothermal power plants.

Retrieved from

https://www.eia.gov/energyexplained/index.php?page=geothermal_power_plants

Varghese, J. (2016). What are the current challenges \& innovations in Geothermal Resource?

Exploration? Retrieved from https://www.researchgate.net/post/ Geothermal

Verkis Consulting Engineers (2014).Geothermal Binary Power Plants. Author. Retrieved from https://www.esmap.org/sites/esmap.org/files/DocumentLibrary/ Iceida-geothermal-binary-overview_small.pdf

Waard, A., Cousijn, H. \& Aalbersberg, I. (2015, December 11).10 aspects of highly effective 
research data. Elsevier. Retrieved from

https://www.elsevier.com/connect/10-aspects-of-highly-effective-research-data

Wada, K., Maedomari, J., \& Furuya, K., (2017). Small Geothermal Power Generation System for Well Head. GRC Transactions, 41, 1-5.

Weebly (n.d.). Geothermal. Retrieved from https://geothermalenergyosu.weebly.com/different-types-of-geothermal-energy.html

Williamson, K.H, Gunderson, R.P., Hamblin, G.M. Darrell L. Gallup, D.L. \& Kitz, K. (2001). Geothermal power technology. Proceedings of the IEEE, 89(2). 1783-1792.

World Bank (2017, January 1). Geothermal. World Bank.

https://www.worldbank.org/en/results/2017/12/01/geothermal

World Energy council (2016). Geothermal. World Energy council. Retrieved from https://www.worldenergy.org/data/resources/resource/geothermal/

Younger, P.L. (2015).Geothermal energy: Delivering on the global potential. Energies.8. 11737-11754. doi: 10.3390/en81011737.

https://geothermalcommunities.eu/assets/elearning/7.10.art1.pdf 